\title{
PÍNDARO P.12.28-32: DEMON Y TIEMPO EN LA CONCEPCIÓN DE LA PROVIDENCIA DE PÍNDARO ${ }^{1}$
}

\section{DANIEL RIAÑO RUFILANCHAS}

Most commentators on the final verses of Pindar's Twelfth Pythian Ode have expressed a discontent with the apparent banality they have perceived in these lines. Yet there remains a number of exegetical challenges in regard to these gnomic verses which render their interpretation eine alte Crux der Erklärung. In this paper we analyze those interpretations which have addressed each of the final verses, and we state our reasons for rejecting each of them either on syntactical grounds or for their lack of internal coherence. In what follows, we shall propose a new interpretation of the entire passage, one which will show how Pindar is ellaborating a topos about the role that Time and Deity play in the fulfillment of Fate.

\section{Introducción}

Colocada al final de la colección de las Píticas, la número 12 es sin embargo una de las primeras obras de Píndaro, fechable en 490 (ó 486). Se trata de una composición monostrófica (como la contemporánea Pítica 6, además de $N .2,4,9, O .14$ e $I .8$ ) de sólo 32 versos en dáctilo-epítritos, que presenta además la particularidad de ser el único de los epinicios conservados dirigidos al vencedor no de una competición atlética, sino de un certamen

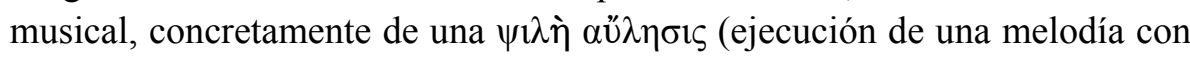

1 Agradezco a los profesores Javier de Hoz (UCM), Julián Méndez Dosuna (USal.) y Emilio Suárez de la Torre (UVall.) su lectura de una versión previa de este artículo y sus valiosos comentarios al texto, sin que ello implique que compartan cada una de nuestras conclusiones. Una completa lista de las referencias bibliográficas hechas a lo largo del texto aparece al final del artículo.

EMERITA. Revista de Lingüística y Filología Clásica (EM) — LXIX 1, 2001

pp. 63-91 
el aulós sin canto). Midas, el auletes vencedor del certamen y destinatario de esta oda no es mencionado por las fuentes antiguas fuera de los escolios a la $\mathrm{obra}^{2}$. La Pítica no hace referencia a su familia ni a una posición social distinguida, lo que resulta extraordinario en Píndaro. Esto, unido al hecho de que el nombre del músico es ciertamente frigio (lo que recuerda el origen de su instrumento) ha llevado a conjeturar que se tratara de un esclavo, o más probablemente un liberto protegido por la poderosa casa acragantina de los Emménidas, quienes a su vez son destinatarios de la mencionada $P .6^{3}$.

El sentencioso final de esta Pítica (versos 28-32) es un texto lleno de dificultades («eine alte Crux der Erklärung» como reconoce Schlesinger al final de su artículo sobre el poema $)^{4}$, y también (y quizá por ello) uno de los pasajes menos apreciados estilísticamente por los estudiosos de Píndaro. Reproduzco el texto establecido por Snell-Mahler, con un aparato distinto del de estos editores ${ }^{5}$.

2 Según la inscriptio de los escolios Midas venció dos veces en Delfos (en las Pitíadas 24 y 25) y quizás también en las Panateneas ( Mezger p. 197 y Gildersleeve p. 364 toman a Midas por el maestro de Lamprocles, de quien a su vez fue discípulo Sófocles, y lo presentan como músico célebre en su época. Modernamente también Luisi lo considera «tra i più famosi auleti dell'antichità» Gentili-Luisi p. 15, cf. Gentili p. XXXVI. Común a todos estos textos es no ofrecer la fuente de la que extraen tales datos. Yo me temo que lo primero no es sino un error surgido al tomar a Midas por Midón, pa-

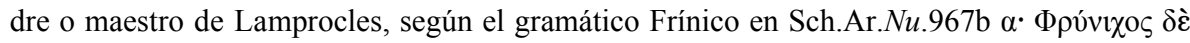

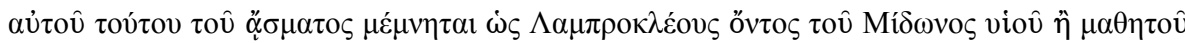
(Cf. Albert, «Lamprocles», REA 23). Quizás no haya otro motivo para creer que Midas realmente gozó de fama que entender ingenuamente (como hacía Böckh) que la curiosa noticia sobre el accidentado modo en que Midas obtuvo la victoria (cf. §2) la tomaron los escoliastas de una inscripción que en Delfos celebraría al músico. El resto de los tratadistas modernos subraya la falta de otras noticias acerca de Midas.

3 También parece dedicada a una persona de condición menos que ilustre la $P .11$, cf. $\tau \grave{\alpha}$ $\mu \varepsilon ́ \sigma \alpha$ v. 52. Para la métrica y una introducción completa a esta oda, remito a la excelente edición crítica de Gentili, pp. 307 ss.

4 Schlesinger p. 285. Lauts escribe: «Die Erklärung dieser Verse hat viele Schwierigkeiten, weil der Gesichtspunkt, aus dem man sie betrachten muss, nicht gehörig vom Dichter bestimmt ist», p. 95; cf. Böck, vol 1 p. 510; Köhnken [1976]: «Ohne Zweifel aber ist Pythien 12 ein schwieriges Lied, dessen Sinn nich 'mit Händen zu greifen' ist» p. 205 (en referencia a la opinión de Radt de que $P .12$ es «verhältnismaßig unproblematisch» p. 117.

5 Sobre el aparato de Snell-Mahler y esp. en este lugar, cf. Pavese p. 72 ss. 


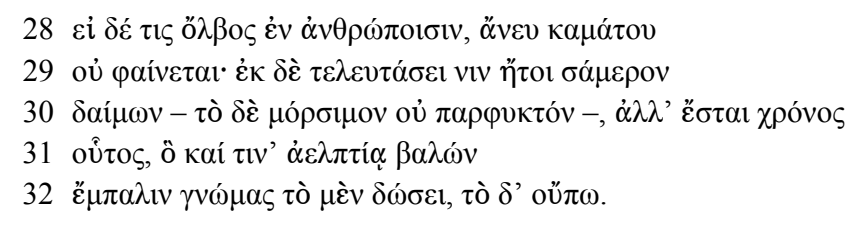

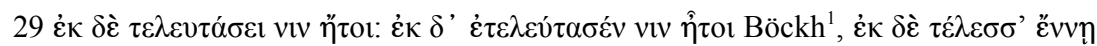

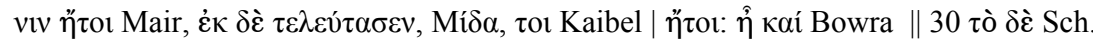

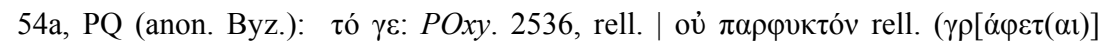

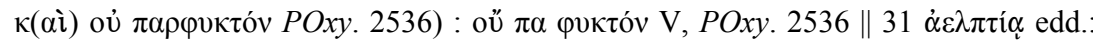

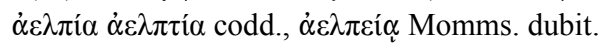

La mayoría de los comentaristas que se han detenido en estos versos han manifestado claramente su disgusto por la inoportuna banalidad de los sentimientos que expresan, o bien piensan que el pasaje está corrupto (cf. infra): "'The fateful is beyond shunning' must be thought inferior even to che sarà sarà, because the pretentious wording may persuade the unwary that something has been said», Norwood p. 60; «We cannot help remarking the abrupt and inconsistent way in which Pindar has attached them [sc. "the concluding verses"] as a coda to his poem», Burton p. 31; «In the moralising that closes the ode [Pindar] seems slightly to lose his head», Farnell p. 152. Si el texto del poeta viene a significar lo que con algunas diferencias de detalle se ha venido entendiendo hasta hoy, tales opiniones no son del todo injustas. Sin embargo, las lecturas modernas del texto presentan serios problemas que dejan abierta la posibilidad de un nuevo enfoque ${ }^{6}$.

Tratar de dar una interpretación de la oda en su conjunto, o de la relación entre el mito central y el final gnómico nos colocaría frente al problema de la unidad de las odas de Píndaro, algo que solo muy superficialmente puede ser

6 Cito solamente dos traducciones. Herwerden: «Procul dubio hoc dicit aut dicere debuit poeta: «hodie quidem, o Mida, eam felicitatem uictoria tua adeptus es, sed nimis ea confidere noli, ineluctabilis enim est fati uis, eritque aliquando in uita tua (ut reliquorum mortalium) tempus quo non omnia similiter ex uoto tibi cedant, sed alia praeter spem tibi dabuntur, alia in praesentia saltem denegabuntur». (p. 50); Köhnken (1971): «wenn es aber überhaupt ein Glück bei Menschen gibt, dann zeigt es sich nicht ohne Mühe: vollenden aber wird es nun wirklich heute ein Gott: am schicksalsbestimmten Tod allerdings kann der Mensch nicht vorbeifliehen: doch es wird diese Lebenszeit sein, die auch manchen mit etwas Unverhofftem treffen und ihm wider Erwarten nur einen Teil seiner Wünsche erfüllen wird» (p. 148). 
tratado aquí por exceder el propósito de estas páginas ${ }^{7}$. En cuanto al final del poema, que es el asunto de este artículo, es evidente al menos que trata de la felicidad y los pesares de los hombres durante su vida, y del modo en que divinidad, tiempo y destino intervienen en ellos; pero es algo mucho menos claro de qué forma entiende Píndaro la relación entre estos poderes y aquel acaecer, o su relación con el mito de Perseo y la victoria de Midas y por ello los especialistas están lejos de tener una opinión unánime ${ }^{8}$. Buena parte de los comentarios y traducciones parten de la suposición de que en el texto hay una (o dos) alusiones implícitas a la vida de Midas: por un lado, cierto evento acaecido durante la ejecución de la obra que refieren los escolios (cf. $\S 2$ comienzo), y por otro lado, una elíptica referencia a alguna aspiración insatisfecha del auletas (cf. $\S 3$ fin). Unos entienden que la oda se recitó en Agrigento tras el retorno del vencedor y para otros es indispensable que la ejecución de la oda ocurriera inmediatamente a continuación del agón. Las diferencias en la interpretación semántica de algunas palabras clave o el valor de algunas construcciones son casi tantas como autores se han ocupado del texto. Determinar el sentido de las máximas en el sistema de valores del autor, o siquiera la conexión entre unas y otras es también un escollo ante el que cualquier lectura crítica titubea.

En este análisis de los versos 28-32 de la Pítica 12 nos centraremos primero en las dificultades gramaticales y de coherencia interna que presentan las diversas explicaciones de los últimos versos, para proponer después una interpretación que difiere de todas ellas en varios puntos y de la que de deriva un sentido que espero resulte más plausible que los propuestos hasta ahora.

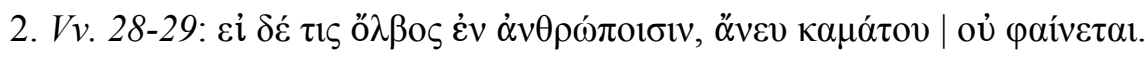

La inscriptio de los escolios (y más tarde el escolio a v. 32) nos cuenta un suceso que habría tenido lugar durante el certamen: en medio de la ejecución de la melodía, la pieza que une los dos tubos del instrumento se rompió, pero

\footnotetext{
7 Para una revisión crítica de las explicaciones sobre el sentido del mito, y su relación con el final de la oda, cf. Köhnken 1971, esp. pp. 147 ss.

8 «Das Gnomenpaar ... hat mit dem Mythos gar keinen Zusammenhang und passt

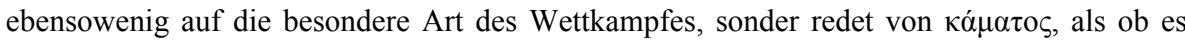
sich um eine harte Sportleistung handelte» Bischoff p. 159.
} 
Midas continuó la melodía soplando directamente en la caña, provocando la

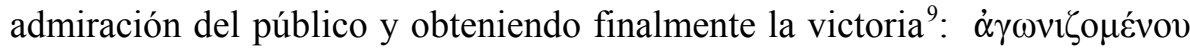

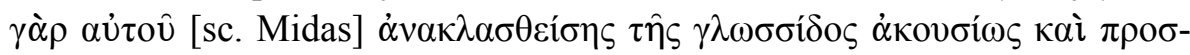

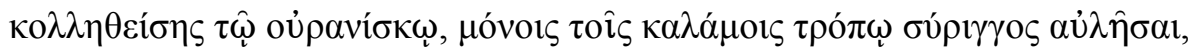

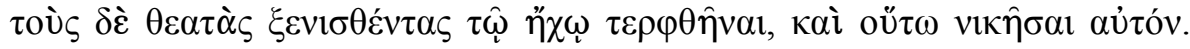
Aunque no faltan quienes ponen en duda la historicidad de la anécdota, la consideran irrelevante, la pasan por alto, o la toman sólo con reservas ${ }^{10}$, una buena parte de los comentaristas y autoridades en Píndaro la consideran auténtica e incluso imprescindible para la interpretación de los versos ${ }^{11}$. Dentro de quienes abogan por la verosimilitud del escolio, todavía cabe distinguir entre aquellos que lo hacen pertinente para la explicación de los versos 2829 y con ello de todo el final (Mommsen, Gildersleeve), o de todo el poema (Gentili 1995, 1996, pp. 109-112; Gentili-Luisi).

La interpretación de toda la oda inteligentemente elaborada por Gentili [1995, 1996], y desarrollada de forma erudita en Gentili-Luisi es a nuestro juicio la mejor fundada de las que conocemos, por lo que le dedicaremos aquí una atención especial. Tal interpretación descansa sobre la exigencia de que tal historia sea cierta ${ }^{12}$, lo que se supone debe demostrar el estudio del segundo coautor, pero en mi opinión las conclusiones de éste más bien rebaten la hipótesis central del artículo. Luisi, dando por hecho que el incidente tal co-

9 Para una discusión sobre la exacta naturaleza del instrumento, y especialmente sobre la función de las $\gamma \lambda \omega \sigma \sigma i ́ \delta \varepsilon \varsigma$, cf. Gentili-Luisi p. 17 ss. y la abundante bibliografía en n. 28.

10 (a) la ponen seriamente en duda, o la toman por una invención del escoliasta: Wilamowitz p. 147, Méautis, p. 226-228; Bradford Welles, p. 85, Thummer, p. 75 n. 52; (b) la consideran irrelevante para la interpretación: Mezger, p. 200; (c) la ignoran: Farnell, Race, Köhnken [1971]; (d) la toman con reservas: Burton, «This story may have some basis in fact... [the ancient commentators] may even have invented it to give [the trite maxims of the last strophe] ... relevance», p. 26, Puech, p. 165.

11 (a) la consideran muy probablemente auténtica: Bowra «quite possible», p. 293, Christ; (b) imprescindible para la interpretación: Mommsen [1852], p. 120, Gildersleeve, Gentili, Gentili-Luisi.

12 Gentili parafrasea así estos versos: «La prosperità e il successo comportano per l'uomo molta fatica: oggi (o domani) il dio può realizzarli, perche non si sfugge al destino. Ma vi sarà un tempo, questo (cioè come questo) que imprevedibilmente percuotendo taluno darà, contro l'attesa, un evento e non altro», Gentili-Luisi, p. 10; «il secondo [enunciato] (v. 30 sgg.) ... è incompresibile senza la notizia, fornitace dagli antichi, dell'incidente occorso a Mida», p. 1011. Según el autor (ib. ibid.) sería este hecho el que hizo famoso a Midas, pero cf. n. 2. 
mo es descrito no es verosímil, (entre otras cosas porque el aulós no puede emitir sonido sin la boquilla, cf. pp. 16, 25), y basándose en la hipótesis, no documentada y probablemente errónea, de que Midas fue considerado uno de los grandes auletes de la antigüedad (pp. 15, 25), pergeña la siguiente explicación: Midas, un gran virtuoso del instrumento (formado éste por dos cañas unidas por una pieza de bronce que sirve a su vez para recibir la embocadura) sustituyó en medio de la ejecución la tradicional boquilla del instrumento por otra doble, la cual proporciona un sonido más armonioso y con la que habría practicado largamente antes de la competición, lo que provocó la natural admiración del auditorio (que evidentemente no estaba al tanto de la maniobra) y en definitiva le concedió la victoria (pp. 24-5). Tan ingeniosa explicación, meramente especulativa, no sólo está en contra de la literalidad del escolio,

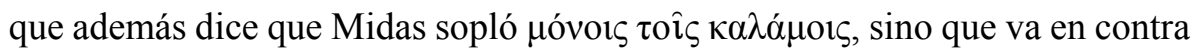
de la posible relación que pueda existir con los vv. 30 ss, ya que si tales hubieran sido los hechos, no se trataría de un éxito en contra de lo esperado, sino, en realidad, de una recompensa al ingenio y la preparación.

Hay además una objeción no menos seria a la hipótesis de Gentili: si se acepta que la oda fue ejecutada el día de la victoria (lo que resulta necesario para su interpretación de бá $\mu \varepsilon \rho o v$ en v. 29) y además se entiende, como hace Gentili, que los motivos principales de la oda, y no sólo las sentencias finales, han sido creadas en gracia al inesperado modo en que Midas venció en el certamen $^{13}$, entonces es preciso admitir que toda la oda, con sus complejos juegos de referencias y su elaborado mito central, fue compuesta el mismo día de la competición, en el tiempo que media entre la victoria y su celebración, lo cual resulta improbable por varios motivos, incluso para quien acepte que una pieza de esta complejidad puede tener tal génesis. En primer lugar, la

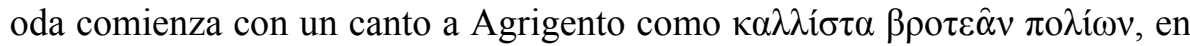
lugar de la esperable alabanza a la ciudad de la victoria, y las palabras de v. 5

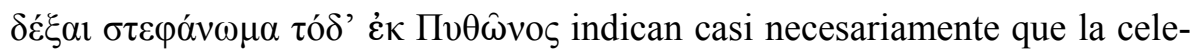
bración no se realiza en Delfos. Por otro lado, los epinicios creados in situ, para ser ejecutados al término de las competiciones, en el mismo escenario de la victoria, responden a una tipología de rasgos bien determinados tanto por las exigencias materiales de este tipo de composición poética (premura del tiempo, etc.) como por las funciones sociales y de comunicación a que res-

13 Gentili, p. XXXVIII ss. 
ponde ${ }^{14}$. Solo tres rasgos formales acercan esta pieza al tipo en cuestión: la relativa brevedad (en el tipo es frecuentemente más breve aún), el carácter monostrófico y el metro. Pero en todos los demás rasgos, de índole material, el poema se aparta por completo del tipo, pues no se celebra al comienzo a Delfos ni a Apolo ( ̋ै $v \alpha$ en el v. 3 debe necesariamente referirse a la propia Agrigento), ni el agón es una competición atlética importante, ni se menciona la familia del vencedor; y por el contrario el mito ocupa una parte fundamental de la obra, la cual termina con una serie de sentencias, rasgos ambos que cuando muy ocasionalmente aparecen, lo hacen de forma incomparablemente más breve y marginal que en esta pieza. Finalmente, todavía cabría suponer que la oda fuera compuesta inmediatamente, pero sólo para ser ejecutada a la vuelta de Midas a Agrigento: ello haría menos graves los problemas del encabezamiento del texto, pero tornaría más acuciante el de la referencia de oó $\mu \varepsilon-$ $\rho v$, y a las dificultades de forma ya mencionadas añadiría la falta de algún elemento que indicara este carácter del poema. Todo ello hace que (aun cuando este extremo no afecte a nuestra interpretación), pongamos seriamente en duda que la obra fuera compuesta el mismo día de la victoria ${ }^{15}$.

Mientras el sentido de ő $\lambda \beta \varsigma_{\varsigma}$ ('dicha', 'felicidad', 'prosperidad') no ofrece

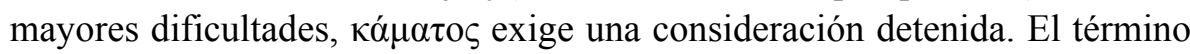
tiene un amplio significado que excede con mucho la noción de "esfuerzo" necesario para la victoria en un agón, que es el sentido que posee en $P$. 5.47, I. 8.1. En otros pasajes de Píndaro lo vemos usado para referirse a los trabajos de Hércules (N. 1.10), las fatigas de Peleo y Cadmo (P. 3.96), el dolor de Cástor ante la muerte de su hermano ( $N .10 .79)$, los peligros de una travesía marina (O. 6.103), o los sufrimientos de las mujeres locrias en la guerra $(P$.

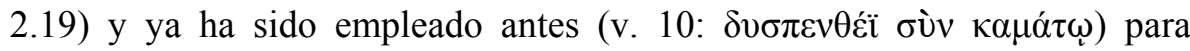
referirse al dolor de las serpientes que cubrían la cabeza de las Gorgonas ${ }^{16}$. Esta repetición del término no es probablemente casual, y del sentido general

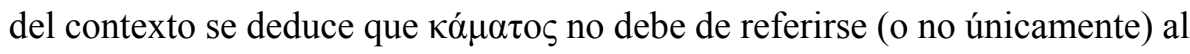

14 Identificó y caracterizó brillantemente este tipo de epinicios Gelzer 1985.

15 Incluso admitiendo que бá $\mu \varepsilon \rho o v$ pudiera tener, en el contexto de la celebración, un sentido más amplio que el de la jornada limitada por las salidas del sol.

16 Cf. Bradford Welles, pp. 92-93. Aunque no comparta siempre el procedimiento de Bradford Welles, ni su interpretación de los versos finales, le cabe a este autor el mérito de haber vuelto a otorgar a las consideraciones éticas y religiosas la relevancia debida en la exégesis de este pasaje. 
esfuerzo en el agón, sino que puede alcanzar a todo lo que se opone a ő $\lambda \beta o \varsigma$ : sufrimientos, penas, angustia, dolor.

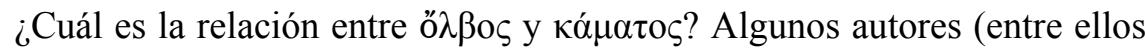
quienes entienden que кó $\mu \alpha \tau o \zeta$ sólo alcanza al esfuerzo del músico) afirman que es la que se da entre el esfuerzo humano consciente que tiende a lograr un propósito y la satisfacción al obtener la recompensa, cf. Christ, p. 231: «generalis sententia de hominum felicitate numquam sine labore paranda» o más claramente Race: «a series of gnomes stressing the hard work necessary for success» (p. 377). Es cierto que todo epinicio exalta el esfuerzo agonístico cuando es coronado por el éxito, y que la relación entre el esfuerzo del competidor y su victoria puede verse como una celebración de este principio, pero en mi opinión, el tono de este pasaje no está puesto al servicio del lugar común "la felicidad sólo se alcanza mediante el esfuerzo", sino que, como muestra en contexto, da voz a una reflexión sobre la relación entre la divinidad y los humanos, y por la función del sistema aristocrático de valores ${ }^{17}$.

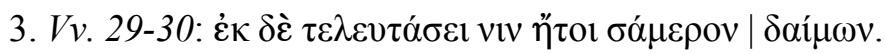

Los editores y comentaristas hasta finales del s. XIX entendieron casi

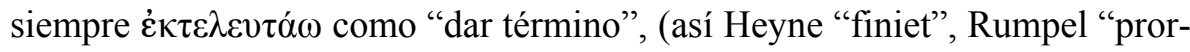
sus ad finem perduco") y generalmente tomaron el sustantivo más cercano кó $\mu \alpha \tau o v$ como referente de viv (Lauts, Mezger, Gildersleeve, Fennell). Tal interpretación, de una óptima sintaxis en lo que al anafórico se refiere, se basaba principalmente en el aparente paralelo de $\dot{\varepsilon} \kappa \tau \varepsilon \lambda \varepsilon v \tau \eta \dot{\sigma} \sigma \alpha \varsigma$ de $M$ frente a

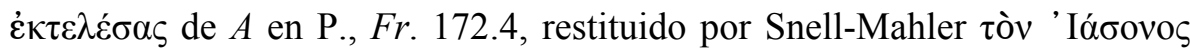
$\varepsilon \cup ̋ \delta$ óov $\pi \lambda$ óov $\dot{\varepsilon} \kappa \tau \varepsilon \lambda \varepsilon \dot{\varepsilon} \sigma \alpha 1 \zeta$ como una forma de $\dot{\varepsilon} \kappa \tau \varepsilon \lambda \varepsilon \dot{\varepsilon} \omega$. Por otro lado, esta traducción (que exige entender $\eta^{\prime} \tau o l=\hat{\eta} \tau o l$, cf. infra.) no da buen sentido: ni se entiende por qué razón el кó $\mu \alpha \tau o v$ del auletes habría de durar después de la victoria hasta la celebración (salvo que la oda se hubiera cantado ese mismo día, lo que rechazan la mayoría de los autores, cf. § 2) ni, sobre todo, es

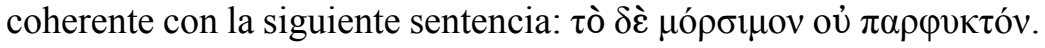

Esta línea de interpretación ha sido casi unánimemente abandonada por

17 Píndaro se refiere con frecuencia a la felicidad que proporcionan los dioses a los hombres piadosos, especialmente en la vejez, pero pasajes como Pi., N. 9.44, redactada en honor

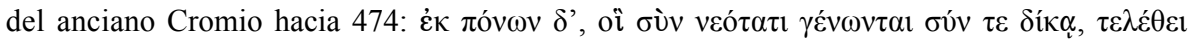

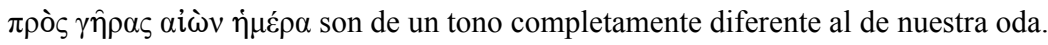


los autores modernos, quienes se inclinan mayoritariamente por dar a $\dot{\varepsilon} \kappa \tau \varepsilon$ -

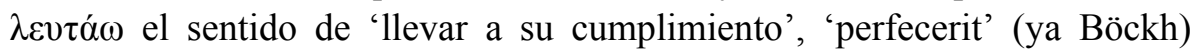
'vollenden' (Wilamowitz), 'bring about' (Slater, LSJ) y hacen de ö $\lambda \beta$ ov el referente de vıv (así Böckh, Lattimore, Bischoff, Cerratto, Puech, Alsina, Bádenas-Bernabé, Race $)^{18}$. Recientemente ha levantado serias objeciones a esta interpretación Pfeijffer (p. 410) con los siguientes argumentos: además de persistir la incoherencia con la sentencia del v. 30, la pesimista formulación

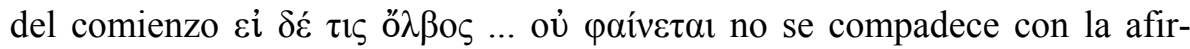
mación siguiente de que el dios dará cumplimiento a la dicha del músico. En

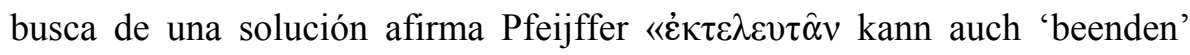

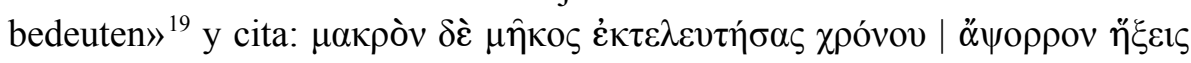

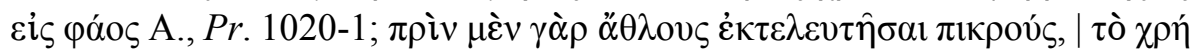

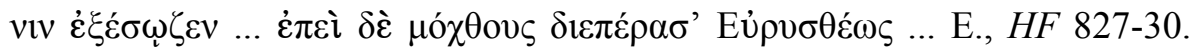
Con tal sentido (referido a ő $\lambda \beta o \varsigma$ ) se solucionarían tales problemas de contenido, pero se plantearía uno nuevo no menos grave: ¿cómo puede explicarse que el Poeta se dirija al vencedor del certamen en el día de su celebración diciendo de forma tan tajante que una divinidad pondrá fin a su dicha? Y además, ¿por qué decirlo precedido de la máxima anterior? Pfeijffer cree encontrar la solución en la misma ambigüedad del verbo: «Die Lösung dürfte darin liegen, daß die Ambiguität, die dem Verb anhaftet, für die Interpretation produktiv gemacht wird: dann bleibt es unsicher ob ein Gott das Glück - sogar heute!- beenden wird oder ob es - sogar heute! realisieren wird. Beide Deutungen sind möglich und relevant». A mi parecer, es excesivamente optimista (dejando cuestiones de sintaxis para más tarde) pensar que la misma ambigüedad que plantea cada una de tales interpretaciones irreconciliables resuelve todos los problemas interpretativos, en lugar de sumarlos. Por otra parte, y en contra de lo que opina Pfeijffer, en nin-

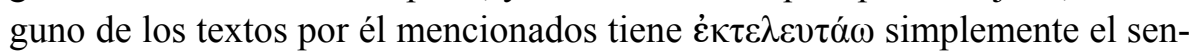
tido 'terminar', 'beenden'. Puesto que el significado de este verbo es de suma importancia para entender el pasaje en cuestión, nos detendremos en él un momento.

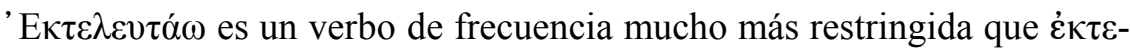

18 Melanchthon (cit. por Bradford Welles, p. 91) ya traducía en 1558 «sed eam [felicitatem] ad exitum perducit.

19 Por la misma traducción se habían inclinado Strohm p. 49, Sandys, «bring that bliss to an end», y Suárez de la Torre. 
$\lambda \varepsilon \dot{\varepsilon} \omega$ (con el que tardíamente tiende a confundirse) o que los verbos simples correspondientes, y cubre solamente una parte del significado de aquél (mas

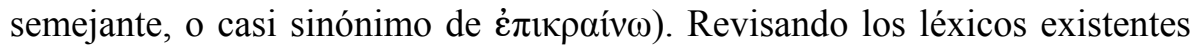
he encontrado 9 testimonios con anterioridad al s. IV d.C ${ }^{20}$ En todos los casos, aquello que se cumple está prescrito por la divinidad, lo que no debe extrañar en el compuesto de un verbo tan ligado al culto como $\tau \varepsilon \lambda \varepsilon v \tau \alpha ́ \omega ;$; en todos los testimonios, el agente es una divinidad o un semidiós que cumple un designio divino. La acción que éste realiza no consiste meramente en poner término a algo, hacer que esto termine en algún punto de su desarrollo, sino en dar cumplimiento al designio divino. En casos como E., $H F$ 827-30 (el

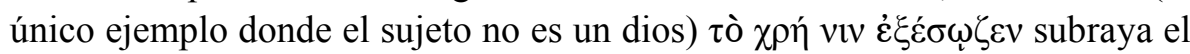
carácter teleológico de la acción. En nuestro caso el designio divino está bien claro, tanto por la oración anterior como por $\tau$ ò $\mu$ ó $\rho \sigma \mu \rho \mathrm{v}$ de la siguiente. Naturalmente $\dot{\varepsilon} \kappa \tau \varepsilon \lambda \varepsilon v \tau \hat{\alpha} \nu \tau$ implica también que el proceso llegue a su término y 'final' es materialmente indistinguible de 'término, perfección del desarrollo' cuando el objeto indica "periodo de tiempo" como en A., Pr. 1020 donde se habla del primer castigo de Prometeo.

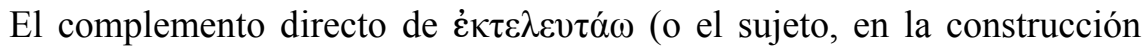
pasiva e intransitiva) es normalmente un pronombre con un referente difuso

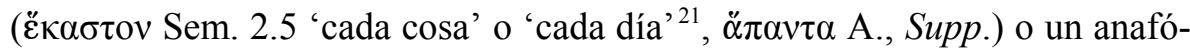

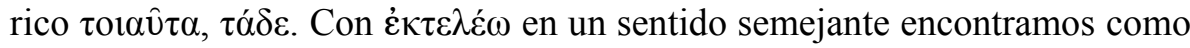

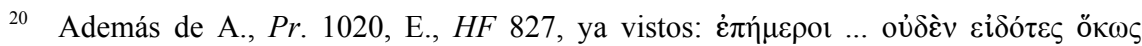

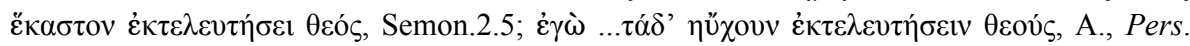

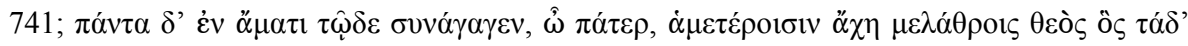

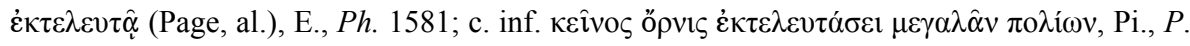

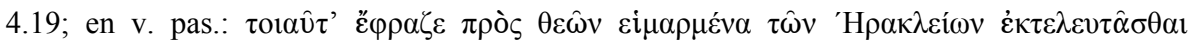

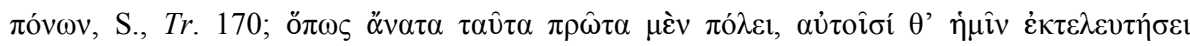
$\kappa \alpha \lambda \hat{\omega} \varsigma$, A., Supp. 411: Con posterioridad, y fuera de los escolios se encuentra muy frecuentemente en Cirilo de Alejandría (más de 40 veces, según el $T L G$ E) y en Juan Damasceno PGM 95.509, 1. 49 en un uso muy semejante al de A., Supp. 411.

21 De forma errónea traduce Pellizer-Tedeschi Semon. 2.5 como «in che modo condurra ciascuno di noi alla sua fine», que da mal sentido: mejor «ignorantes de cómo terminará la divinidad cada cosa», Adrados, p. 153, cf. Gerber 1999. Solamente un ejemplo cabría aducirse de $\dot{\varepsilon} \kappa \tau \varepsilon \lambda \varepsilon v \tau \alpha \dot{\omega} \omega=$ 'terminar'. Ellendt (que es autoridad no pequeña en lexicografía) traduce el verbo en S., Tr. 170 como finio. Me parece ciertamente preferible entender (con

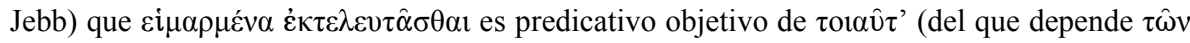

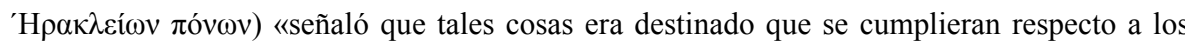
trabajos de Hércules». 


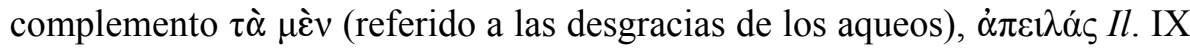

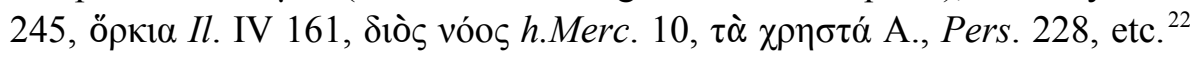

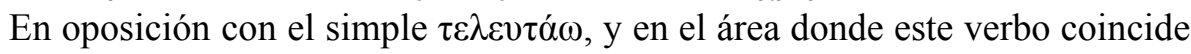

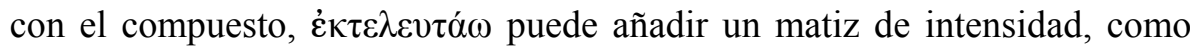
parece deducirse de $I l$. IV 161 (cf. infra) donde, según creo, se ejemplifica esta área semántica de coincidencia ${ }^{23}$.

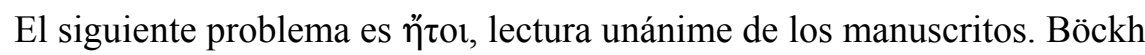

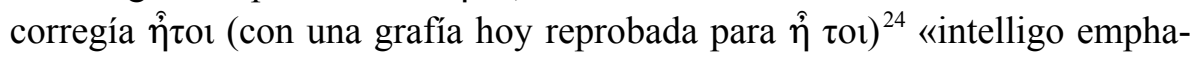

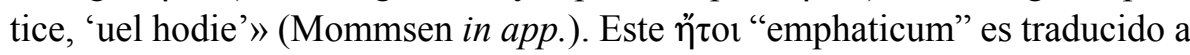
las lenguas modernas de dos formas muy distintas: normalmente, siguiendo a Christ ${ }^{25}$ se da a la frase un tono interrogativo o se añade un matiz de duda ('vielleicht', 'acaso'). A pesar de lo improbable de este valor ${ }^{26}$, es el sentido que sigue la mayoría de los traductores, y algunos comentaristas (Bischoff, Farnell, Puech, Bremer, Suárez de la Torre, Pfeijffer, Alsina, Lattimore, Sandys); otros autores entienden en cambio que el matiz es intensivo, y traducen “en verdad” (Bádenas-Bernabé) “wirklich” (Köhnken [1971], pp. 148 n. 134, 123-5) etc. Esta traducción es en abstracto posible, pero el valor de tal inter-

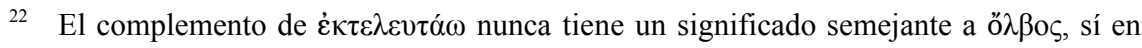

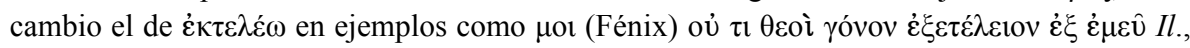

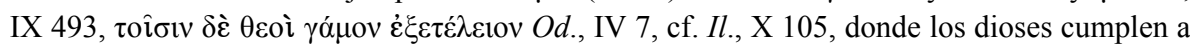

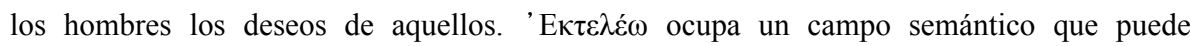
extenderse a casi todo tipo de objetos, sin que el agente sea una divinidad, cf. referido a tareas que deben ser ejecutadas por los hombres: ״̈ $\varepsilon \theta \lambda$ ov Od., XXI 135, 180, 268, $\pi \lambda$ óov Pi., Fr.

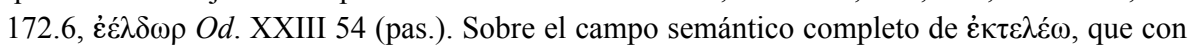
frecuencia tiene el sentido de 'terminar' (Od. II 98, XIX 156, XXIV 146, etc.) véase DGE vol. 7 (en preparación) s.u.

23 Puede traerse esta cita como contraargumento a la objeción de Pfeijffer «Die Komentatoren versuchen diese Diskrepanz dadurch aufzuheben, daß sie das Präfix દ́к maximal belasten ... diese Überspizung der Bedeutung des Präfixes wird aber von der einzigen pindarischen Parallelstelle für das verb $\dot{\varepsilon} \kappa \tau \varepsilon \lambda \varepsilon v \tau \hat{\alpha} \nu$... nicht bestätigt».

24 Cf. Denniston, p. 553. Bradford Welles (p. 94) no ve dificultad en este verso.

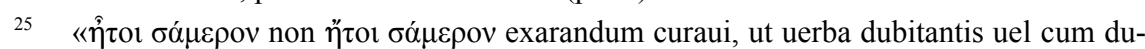
bitatione interrogantis essent, cui dubitationi poeta ita respondet, ut hoc quidem, num hodie deus perficiat, dubium esse concedat, sed certe esse asseueret».

26 «Vellem exemplis idoneis uir eximius [Christ] demonstrasset ฑ̊ $\tau o 1$, quod apud Pindarum semper et, nisi fallor, apud omnes est asseuerantis ... dubitationem significare posse, Ita

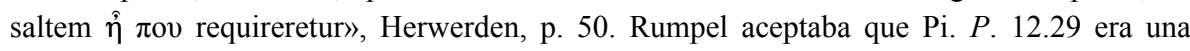
excepción a la posición de ๆ̄iot. 


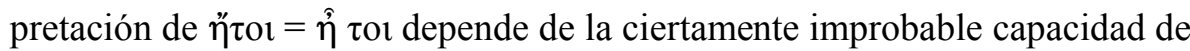
la partícula para aparecer en este lugar de la frase ${ }^{27}$. Wilamowitz (a quien siguen Schlesinger, Burton, Slater, Bradford Welles, Race, Gentili) que ni

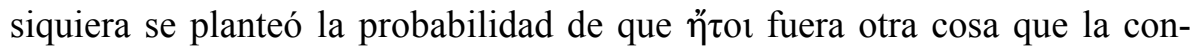
junción disyuntiva, entendía que el poeta se interrumpía antes de expresar el segundo término de la disyunción: «die zweite Alternative wird formell nicht

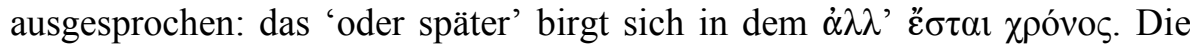

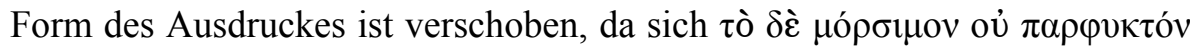
vordrängte, und dann wird diese Zukunft zwar die Hoffnungslosigkeit» (p. 147). Yo tampoco creo que el anacoluto suponga una dificultad insalvable, pero no veo fácil seguir en su traducción ${ }^{28}$ el curso de las ideas del poeta, quien, como proponía Gildersleeve, estaría refiriéndose veladamente a un deseo insatisfecho de Midas $^{29}$. Gentili no ofrece ningún argumento para explicar por qué Píndaro puede haber omitido el segundo término de la disyución.

La interpretación de $\sigma \alpha ́ \mu \varepsilon \rho o v$ trae a cuestión la ocasión del poema ${ }^{30}$. La palabra no ofrece dificultades para quienes entienden $\eta^{\prime} \tau o \iota=\hat{\eta} \tau o \iota$ con matiz enfático si "hoy" se refiere al día de la celebración de la victoria; pero resulta

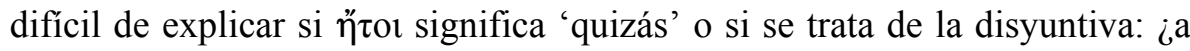
qué debe esperar Midas en el día de la celebración para ver realizada su dicha? Ya hemos dicho que algunos autores entienden que Midas espera algo más, pero, aunque es frecuente que el poeta desee futuros triunfos en certámenes mayores, en ninguna Oda se supone que el triunfo no haya llenado de satisfacción al vencedor, siquiera temporalmente. Böckh² entendía «mora non

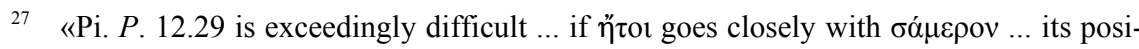
tion is unparalleled», Denniston, p. 554. Radt lo califica de «sehr tendenziöse Übersetzung» p. 118. Cf. la conj. de Bowra en ap. crit.

${ }^{28}$ «Wenn es ein Glück auf Erden gibt, so ercheint es nicht ohne Mühe, und der Dämon wird es entweder heute vollenden - aber das Schicksal ist unentrinnbar, und doch wird eine Zeit kommen, die auch den umstimmt, den sie jetz hoffnungslos gemacht hat, und ihm manches gewären, anderes immer noch nicht», Wilamowitz, p. 147.

29 Hummel, p. 408, se declara a favor de la explicación de Schröder, «nam respondent

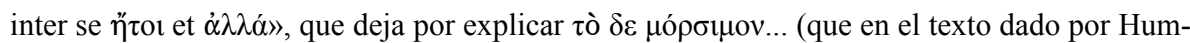
mel está omitido).

30 Para Bowra, p. 161 y la mayoría de los intérpretes, la oda se recitó al regreso del campeón al hogar, probablemente en algún festival en honor de los dioses. Kaibel refiere $\sigma \eta ́ \mu \varepsilon \rho o v$ al día de la victoria: «ist vielleicht gar nicht gnomisch, sondern redet von der heutigen Wirklichkeit des Sieges». De la misma manera, Bischoff, p. 160, Mezger, p. 200. 
longa sed breuissima» (p. 347), lo que tampoco aclara el problema, y Gentili afirma expresamente (siguiendo al escoliasta) que «il carattere strettamente referenziale dei versi conclusivi si coglie nelle argute allusioni all'attualità

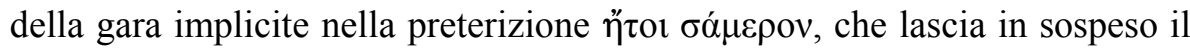

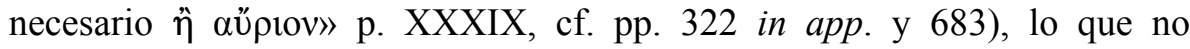
consideramos asumible por las ya alegadas razones $(\S 2)$ y por las que además expondremos en $\S 5$.

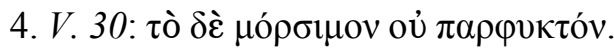

Las dificultades de este pasaje son igualmente de tipo textual e interpretativo. Casi todos los comentaristas recalcan la abrupta forma en que las palabras aparecen intercaladas en el discurso. La lección $\delta \varepsilon ́$ es la aceptada por todos los editores modernos, excepto Turyn, Köhnken [1971] p. 148 y Gentili, quienes prefieren $\gamma \varepsilon$ (antes también Heyne). Ésta es también la lectura del comentario (o un resumen del mismo) de Teón el hijo de Artemidoro (POxy. 2536, II d.C.). Además de las razones paleográficas, Pavese la considera también (correctamente, a mi juicio) «preferibile per il senso» ${ }^{31}$.

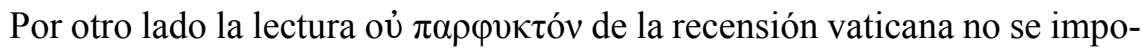

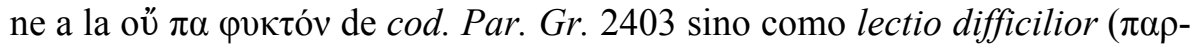

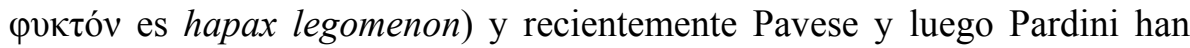
argumentado firmemente en favor de esta última lectura, que es la de POxy. 2536 (pero cf. Gentili p. 684).

Los ejemplos utilizados por los modernos léxicos para ilustrar los usos de $\mu$ ó $\sigma \mu$ o son escasamente representativos del amplio espectro de realidades a las que se puede referir, pero en esencia $\tau$ ò $\mu$ ó $\rho \sigma \mu o v$ es la parte que le corresponde a cada cual, aquello que está prefijado para cada uno por la divinidad, casi siempre (como aquí) de forma ineluctable ${ }^{32}$, y naturalmente es el $\delta \alpha i ́ \mu \omega v$ (sustantivo derivado de $\delta \alpha i ́ o \mu \alpha$, 'repartir') quien lo distribuye entre los hombres.

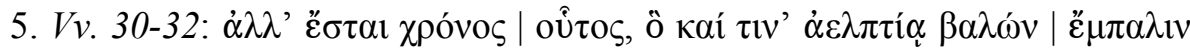

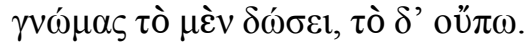

31 Pavese se refiere (p. 72) a un futuro comentario de $P .12$ «in pubblicazione» que no he podido encontrar. Wilamowitz considera tó $\gamma \varepsilon$ "unverständlich", p. 147 n. 1.

32 cf. Dietrich, p 262, 269. 
$\alpha \lambda \lambda$ ’ $\check{\sigma \tau \tau \alpha l: ~ S i ~ s e ~ r e f i e r e ~ a ~ M i d a s, ~ e l ~ f u t u r o ~ n o ~ o f r e c e ~ o t r a ~ d i f i c u l t a d ~ q u e ~}$ identificar cuándo el poeta pasa de utilizar las máximas en sentido general a dirigirlas al músico. Si se toma como una máxima de alcance genérico, debe entenderse como futuro gnómico ${ }^{33}$, cf. $O .6 .85,7.3$.

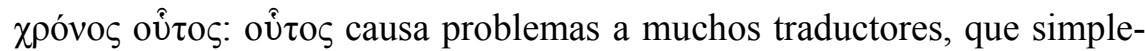
mente lo ignoran (Puech, Sandys, Werner, Alsina, Bremer). Hay varias interpretaciones radicalmente opuestas de estas palabras. Por un lado, la de quie-

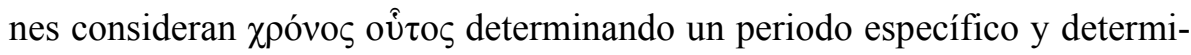
nable de la vida: "diese Zeit = dieses Leben, die zukünftige Lebenszeit" ${ }^{34}$. Tal traducción parece muy arriesgada, y parte de un paralelo que plantea un número de dificultades semejante al de este texto $(O$. 1.115). Más común-

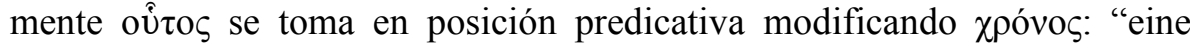
solche Zeit" Lauts, etc. (cf. $O$. 4.24). Gentili lo considera una aposición a

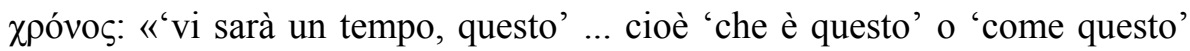
che è quanto dire 'come oggi', il giorno della gara". Esta interpretación, sugerente en consideración al lugar de oủto en el verso, conlleva todas las dificultades consideradas en $\S 2$ y presenta una semántica ciertamente inusual (a mi juicio P., P. 4.289, el pasaje alegado como paralelo, no es comparable).

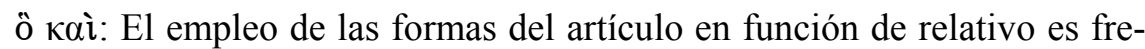
cuente en Píndaro, por lo que nadie ha discutido que ö = ŏ $\varsigma$ y su antecedente sea por tanto $\chi$ póvos.

$\tau \imath v^{\prime}$ : Los editores imprimen unánimemente $\tau \imath v^{\prime}$ lo que comentaristas y

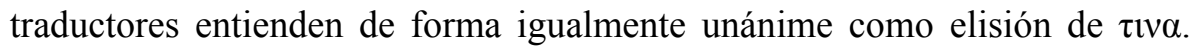
Buena parte de los comentaristas del s. XIX y comienzos del XX (y algunos de los más recientes) ven el pronombre como una alusión oblicua al ganador ${ }^{35}$. En general, sin embargo, este $\tau \imath v \alpha$ es considerado impersonal, conforme al carácter de una máxima. Solamente Mezger entre las ediciones que he podido consultar, acepta un valor distinto cuando enmienda el texto de Christ

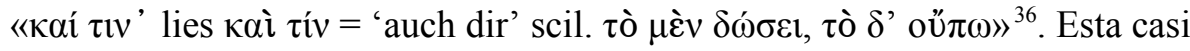
unanimidad de los editores es tanto más llamativa cuanto que es exclusiva-

33 Cooper, $\S 53.10 .4$.

34 Köhnken [1971], p. 148.

35 Fenell, «there is often a sinister effect about this idiom, but not here». Gildersleeve,

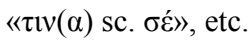

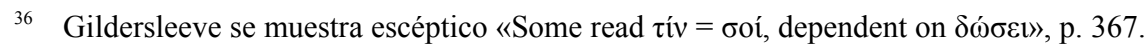

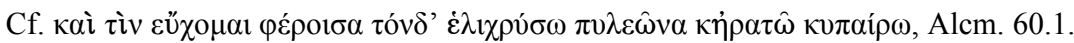


mente este $\tau \imath$ el elemento que podría significar una alusión personal al destinatario de la oda. Este punto, descuidado por los comentaristas, no puede ser pasado por alto.

En todos los epinicios pindáricos de varias estrofas, la mención del vencedor al final de la oda (a él directamente o a su familia) es explícita, clara y no puede dejar dudas en el auditorio sobre el referente. La forma que puede adoptar la mención es muy diversa: en unos casos es un apóstrofe deseando al ganador más triunfos, en otras se le toma como el destinatario último de advertencias de valor universal, etc. Si dejamos al margen las odas incluidas en la colección sin ser auténticamente epinicios y las composiciones más cortas, de una tríada o pocas estrofas ${ }^{37}$, en los epinicios esta referencia al vencedor aparece sin excepción, generalmente en la última tríada o en el épodo de la penúltima, cuando no lo ha hecho antes ${ }^{38}$. La única excepción aparente es la $P .2$, dedicada a Hierón, en la que no se hace alusión tampoco al lugar de celebración de los juegos, y que no es, con toda probabilidad, un epinicio $^{39}$. En casi todos los casos se utiliza un nombre propio, y en el resto una alusión no menos transparente, de tono encomiástico, usando un pronombre, un vocativo, etc ${ }^{40}$.

37 Cf. Gelzer p. 96 para los primeros. Las segundas son: O. 4, 11, 12, 14, P. 7, I. 3. En todas ellas hay una larga alusión al vencedor o su familia en uno o varios lugares.

38 Donde no he señalado otra cosa, Píndaro emplea el nombre del ganador, de su familia

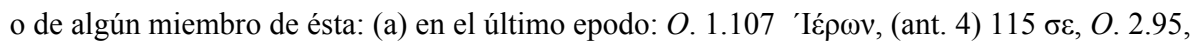
O. 3.43, O. 5.23, O. 7.93, P. 4.298, N. $4.90 \pi \alpha$ ' (tras repetidas menciones a su familia), $N$.

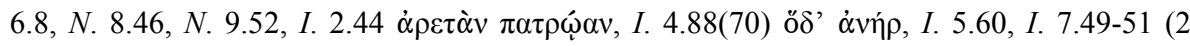

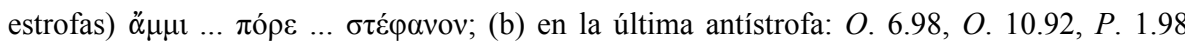
(verbo en 2 a pers.), N. 5.43, I. 1.61, I. $6.62 \dot{\alpha} \gamma \lambda \alpha o i ̀ ~ \pi \alpha \hat{\imath} \delta \varepsilon \varsigma . . . ;$ (c) en la última estrofa $O .9 .87$,

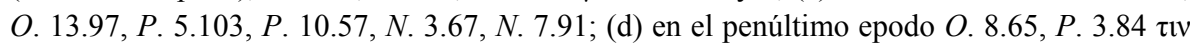

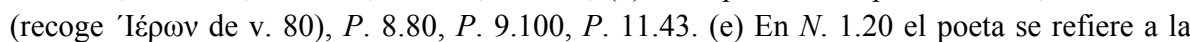
casa del vencedor $\theta u ́ \rho \alpha 1 \zeta \dot{\alpha} v \delta \rho o ̀ \varsigma ~ \varphi ı \lambda o \xi \varepsilon i ́ v o v$ en la $2^{\circ}$ estrofa (la antepenúltima) y es también reseñable (como lo es el carácter de toda la oda) la larga alusión a la familia del vencedor Teeo en la $3^{\circ}$ estrofa (antepenúltima triada) de $N$. 10. (f) En las composiciones monostróficas esta mención al ganador se hace a lo largo de toda la $N$. 2, la última estrofa de $I .8 .66$ y penúltima de $P .6 .44$.

39 En la $N .11$ (que sin duda no es un epinicio) hay una alabanza continua al nuevo prítane Aristágoras, que se detiene en la última tríada, de carácter mítico y gnómico.

40 Un caso notable es $P$. 3, que tampoco es propiamente un epinicio y como la anterior Pítica está dedicada también a Hierón: su nombre no se menciona hasta v. 80 (cf. infra) y

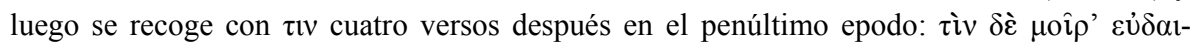


Aunque la estructura habitual de los epinicios podría invitar a corregir aquí el $\tau \imath v^{\prime}$ de los editores por $\tau \imath v$ (= $\sigma o l$, lo que como hemos dicho rechazan comentaristas y traductores modernos, aunque la sintaxis no es obstáculo), hay que hacer varias consideraciones previas. ¿Es necesario suponer que la referencia al ganador en la parte final de la obra es en Píndaro un elemento indispensable de cualquier tipo de epinicio (en el sentido estricto del término)? Eso parece sugerir la mayoría de los textos, pero quizás esta inferencia se deba a la acumulación de datos sesgados por factores externos que han jugado un papel determinante en la transmisión de los epinicios pindáricos, que estaban dedicados casi en su totalidad a notables personajes de la sociedad de la época ${ }^{41}$. Es indiscutible que el respeto a esta preeminencia de ciertas familias debía jugar un papel en la forma del epinicio. Yo me inclino a pensar que después del obligado saludo al vencedor o a su patria (que no siempre figura tan al comienzo de la oda como en la $P$. 12) había consideraciones externas que podían determinar la aparición o no de una segunda alusión al cierre de un canto solemne recitado en público y en una ocasión cargada de significación religiosa. Quizás el origen menos que ilustre de Midas u otro hecho que desconocemos sea uno de los factores que expliquen por qué en esta (por lo demás breve) oda no aparezcan más referencias a su destinatario después de ser saludado sencillamente como $\varepsilon \cup ̉ \delta o ́ \xi \omega$ en v. 5. Ante tales consideraciones (además, evidentemente, de las paleográficas), y aun estimando que la probabilidad de que el único indicio que empleara el poeta para dirigirse ahora al vencedor fuera este pronombre son en mi opinión muy escasas, considero acertado que haya prevalecido la lectura $\tau \imath v(\alpha)$, que deja el final de la oda sin una referencia directa a Midas.

$\dot{\alpha} \varepsilon \lambda \pi \tau i \alpha \alpha \beta \alpha \lambda \omega ́ v:$ «percutiens aliquem re non exspectata» Böckh. Los códices transmiten $\dot{\alpha} \varepsilon \lambda \pi_{i} \alpha, \dot{\alpha} \varepsilon \lambda \pi \tau i ́ \alpha$. Entre los editores modernos, Puech y Turyn se han inclinado por la corrección de Mommsen $\alpha \varepsilon \lambda \pi \varepsilon i ́ \alpha$. . Fuera de aquí, $\dot{\alpha} \varepsilon \lambda \pi \tau i ́ \alpha$ sólo está testimoniado en Archil. 163.3. con el sentido de "acontecimiento inesperado".

$\ddot{\varepsilon} \mu \pi \alpha \lambda \imath \nu \gamma \nu \omega ́ \mu \alpha$ : $\Gamma \nu \omega ́ \mu \eta$ es un término frecuente en Píndaro, que puede referirse tanto a la esfera del conocimiento como a la de los deseos, la opinión, etc. Gildersleeve, Fennell y la mayoría de los comentaristas parecen en-

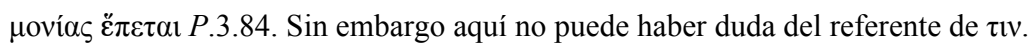

${ }^{41}$ Además de esta Pítica, otra excepción puede ser I. 7. 
tender que se trata de los deseos de Midas ${ }^{42}$. Lo inesperado de los hechos que acaecen a los hombres y su impotente capacidad de previsión son dos elementos recurrentes en Píndaro ${ }^{43}$.

$\tau$ los pocos lugares donde los comentaristas parecen haberse puesto de acuerdo, aunque examinado más de cerca, tal acuerdo es sólo aparente y en realidad existen dos interpretaciones completamente distintas ( ¡de las que debo discrepar!). El acuerdo entre los exégetas se limita en realidad a reconocer que este pasaje presenta una variación del conocido giro, típicamente pindá-

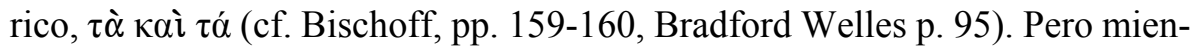
tras unos entienden que se habla siempre de bienes (Sandys, Bádenas-Bernabé) o más oscuramente de "una cosa... otra..." 44 , otros entienden que hay una dicotomía más profunda: «It is usual in these cases to suppose that the first $\tau \dot{\alpha}$ is not the same as the second $\tau \dot{\alpha}$, and one translates 'good and bad' or something of the sort, but Pindar, it should be marked, does not say that, any more than he does in the present passage», Bradford Welles, p. $95^{45}$. A mi juicio, es aventurado, desde el punto de vista sintáctico, querer ver en este $\tau$ ò $\mu \grave{\varepsilon} v \ldots$... $\delta$ ' ... el giro pindárico, que en el resto de los casos ${ }^{46}$ aparece en plural y nunca con el juego de partículas que indica nos hallamos ante una

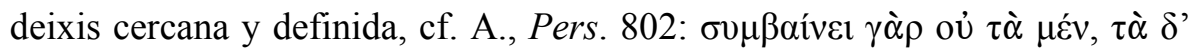

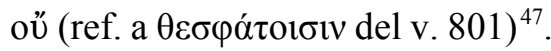

Oü $\pi \omega$ presenta de nuevo una dificultad, y el sentido de todo el pasaje se ve gravemente alterado según el valor que se le quiera dar. En 1966 Bradford

$42 \varepsilon \check{\varepsilon} \mu \pi \alpha \lambda \mathrm{lv}$ solamente aparece en dos ocasiones en la obra de Píndaro, la primera de ellas (O. 12.10-11) en un contexto semejante.

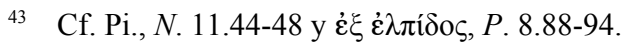

44 Así Alsina; cf. «nous donnera ceci - et nous fera attendre encore le reste!», Puech, etc.

45 Sigue el autor: «These closing lines of Pythian 12 are not a platitude. They represent Pindar's trying to escape from an awkward dilemma. As he began the sentence, it was evidently to be completed only in the sense that gods give men both good and bad. This he refused to do, an in consequence interrupted his train of thought twice, and finally left incomplete».

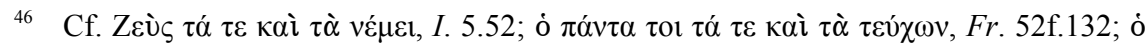

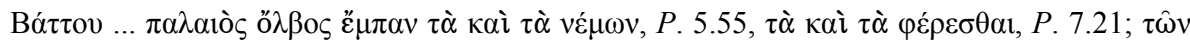

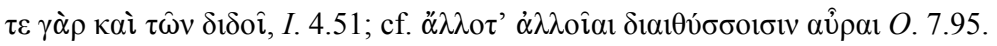

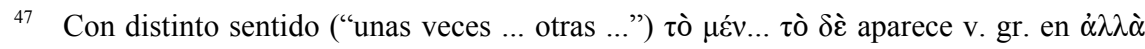

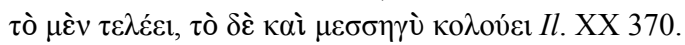


Welles contabilizó el número de traducciones que vertían el significado de oü $\pi \omega$ como "no, nunca" y como "todavía no": «thus far the score is 10 to 6 in favor of 'not'» (p. 90). Posteriormente, la mayoría de las traducciones se han decantado (como hacía el propio Bradford Welles) por "todavía no" de forma mayoritaria ${ }^{48}$. Esta interpretación encaja mejor con la disyuntiva de los vv.

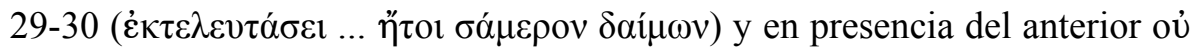
es sintácticamente preferible a la otra. El principal problema que a mi juicio plantea, es que si entendemos que $\tau$ ò $\mu \grave{\varepsilon} v$..., $\tau$ ò $\delta$ ' ... habla exclusivamente de "bienes" o "aspiraciones", el sentido resulta extraordinariamente optimista, y si lo comparamos con los versos anteriores "no hay dicha sin dolor; el destino no tiene escapatoria; el tiempo te dará unas cosas ahora, pero otras todavía no (e.e., te las dará más tarde)", se diría que es incoherentemente optimista. Quienes se inclinan por oü $\pi \omega$ como negación enfática entienden casi unáni-

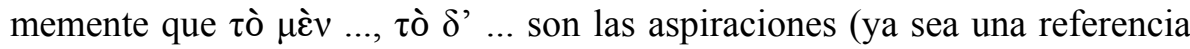
general a los deseos humanos, ya sea a los de Midas en particular ${ }^{49}$.

\section{Principales aporías que persisten.}

Las principales aporías interpretativas que aún persisten después de eliminar las interpretaciones que nos parecen menos fundamentadas se pueden resumir de la siguiente manera: ¿Por qué se interrumpe Píndaro en mitad de la oración de los versos 29-30? ¿Cómo es posible hacer de ő $\lambda \beta o v$ el antecedente de viv sin ningún elemento que previamente nos indique que el poeta pasa ahora a referirse a Midas? Si suponemos que la disyuntiva no terminada se refiere a la posibilidad de alcanzar una victoria en un certamen más importante (o alguna otra expectativa del auletes), tenemos un uso sin paralelo de $\dot{\varepsilon} \kappa \tau \varepsilon \lambda \varepsilon v \tau \hat{\alpha} v$, y un caso único en que el poeta supone que la presente victoria no ha colmado de satisfacción al vencedor. Por otro lado, si estas $\gamma v \hat{\omega} \mu \alpha \mathrm{l}$ se dirigen a Midas, se han de suponer uno (o dos) eventos de la

\footnotetext{
48 No incluidos en la relación de Bradford Welles: (a) "todavía no": Wilamowitz, Werner, Puech, Alsina, Bernabé-Bádenas, Bremer, Suárez de la Torre; (b) "no": Sandys (a quien sigue Greene p. 71), Köhnken 1971, p. 148, Gentili. Esta es también la interpretación

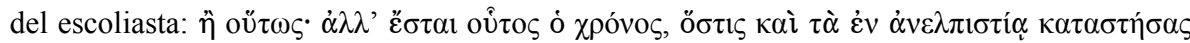

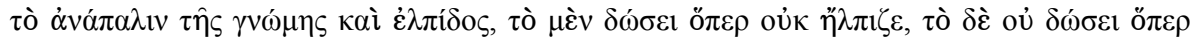

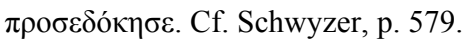

49 Ignoro como Hummel llega a la conclusión: «le choix de l'une ou de l'autre traduction ne modif[ie] guère le sens général de la phrase», p. 311.
} 
vida del músico, que no han sido mencionados por el poeta, y una alusión igualmente críptica mediante $\tau \imath v \alpha$ para entender la oda (cf. $\S ~ 2,3$ ); Igualmente, si el poeta pasa en estos versos a dirigirse al destinatario de toda

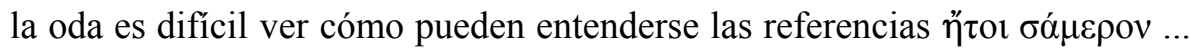

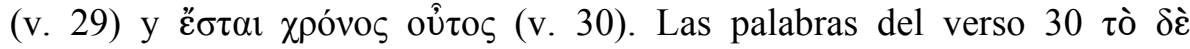

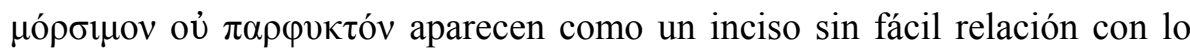
anterior; y la idea de que la divinidad concederá unos bienes ahora, y otros más tarde no guarda fácil conexión con la idea expresada antes de que en la

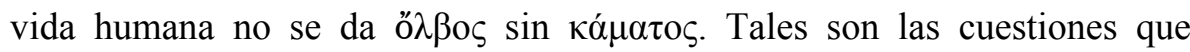
intentamos resolver a continuación.

\section{Una propuesta de interpretación.}

La totalidad de las interpretaciones analizadas hasta ahora tropiezan en su intento de conectar las $\gamma \nu \hat{\omega} \mu \alpha \mathrm{l}$ de estos versos con la esperable referencia final a la victoria de Midas en la competición. La ingeniosa conjetura de Kaibel (cf. §1, la acepta Herwerden) nacía de la perplejidad ante la falta de una mención más directa al vencedor. Ahora bien, es posible que buena parte de las dificultades de interpretación se desvanezcan si no intentamos encontrar al final de esta oda, peculiar o única por varios factores externos (cf. § 1) una inexistente referencia inmediata a la victoria de Midas o una advertencia al ganador. En la interpretación que sigue, tanto el sentido de las máximas tomadas cada una por separado, como el conjunto de las mismas, se entienden como declaraciones de un valor universal.

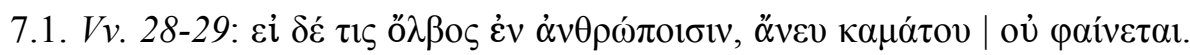
"Si hay alguna felicidad entre los hombres, no aparece sin dolor".

En la primera máxima, Píndaro enuncia una ley universal en la forma condicional propia de la legislación arcaica griega (pero en presente de valor intemporal, no infrecuente en $\gamma \nu \hat{\omega} \mu \alpha \mathrm{l})^{50}$ de la que el resto de los enunciados casi se desprende como corolarios. No se afirma que la dicha vendrá gracias al esfuerzo, o después de él, y en definitiva ni siquiera se afirma que ő $\lambda \beta \beta \varsigma \mathrm{y}$

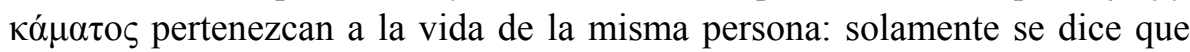

50 O como afirma Bradford Welles «a kind of comic law», p. 92. Acerca del valor de

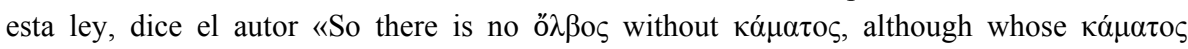
remains a question», Bradford Welles p. 93. 
ambos elementos deben aparecer conjuntamente en la vida humana. El contenido evoca la famosa escena homérica de $I l$. XXIV 527-533, en la que Zeus extrae de dos $\pi i \theta$ or los dones que reparte entre los hombres: "pues dos pithoi están fijos en el umbral de Zeus: uno contiene los males y otro los bienes que nos obsequian. A quien Zeus, que se deleita con el rayo, le da una mezcla, unas veces se encuentra con algo malo y otras con algo bueno. Pero a quien sólo da miserias lo hace objeto de toda afrenta". La vida humana como sucesión y mezcla inevitable de bienes y males es un concepto recurrente en el pensamiento griego, que aparece varias veces en la obra de Píndaro. Frente a la concepción fatalista de la Ilíada (o la "sabiduría de los antiguos" de $P$. 3.80-83), el enunciado Pindárico de la $P .12$ resulta incluso reconfortante. El final de la Pítica octava (fechable en 446) termina con una larga serie de reflexiones sobre la condición del hombre. La expresión aquí es más elaborada que en el final de $P .12$ y las ideas contrastan de forma más clara: se afirma que es el demon quien proporciona la dicha a quien consigue lo que perseguía con ahínco (vv. 73-6) para, a continuación, describir la desgracia del perdedor y contraponerla a la dicha del competidor victorioso. "O $\lambda \beta 0 \varsigma$ y $\kappa \alpha ́ \mu \alpha \tau o \zeta$, dispensados al hombre por fuerzas divinas y entendidos en una oposición absoluta de la que el agón es una metáfora, son ahora los dos elementos sobre los que se articula el final de Pítica 12.

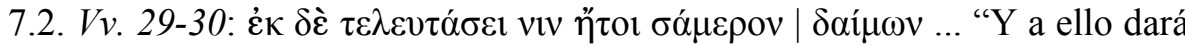
cumplimiento, ya sea hoy una divinidad ..."

Salvo que se considerara corrupto el pasaje, para lo que no hay base paleográfica, ni es necesario para el sentido, solamente cabe una interpretación

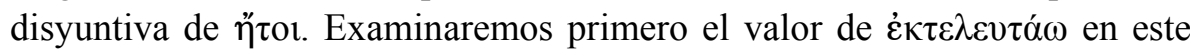
lugar para ver luego cuál es el referente de viv.

El significado de $\dot{\kappa} \kappa \tau \varepsilon \lambda \varepsilon v ́ \tau \alpha \omega$ como verbo causativo referido a la voluntad de la divinidad está como hemos visto (cf. $§ 2$ ) indisolublemente unido a la

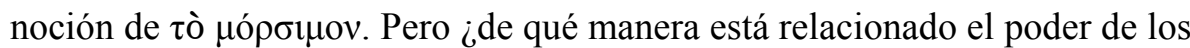
dioses con el destino de los hombres? Si todo lo que acontece está gobernado por los dioses, pero es dolorosamente evidente que no todo lo que ocurre es justo, ni el culpable es castigado o el justo recompensado, ¿qué clase de divinidades son éstas? ¿Son omnipotentes o hay fuerzas que escapan a su poder, y ellos sufren también como los humanos? ¿O existe una doble ley, una que gobierna el mundo perfecto de los dioses y otra que permite la injusticia entre 
los hombres? Que la relación entre el poder de la divinidad y la justicia entre los hombres es algo que ha preocupado a todas las civilizaciones en cualquier época no requiere argumentación, pero es conveniente examinar dos ejemplos que por las similitudes formales con el texto de Píndaro resultan pertinentes para advertir el valor del pasaje en la evolución de un topos en el pensamiento griego desde Homero hasta el siglo V.

En el pasaje homérico antes citado (el lamento de Agamenón ante Menelao en aparente agonía) leemos:

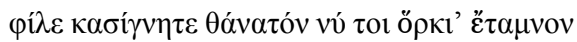

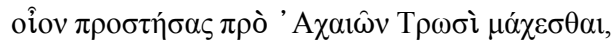

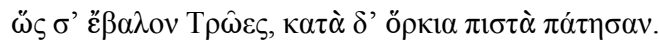

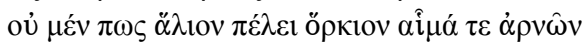

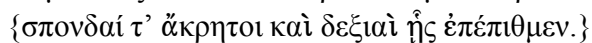

160

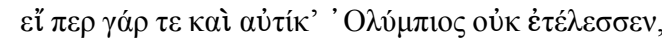

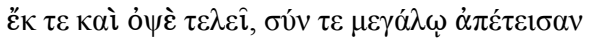

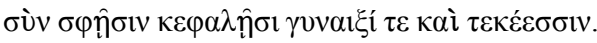

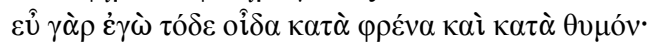

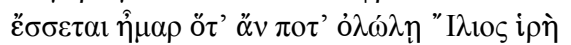

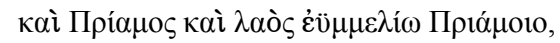

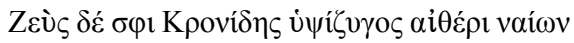

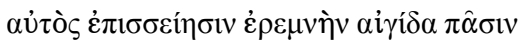

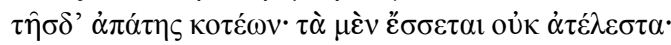

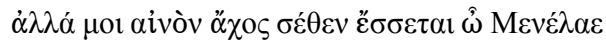

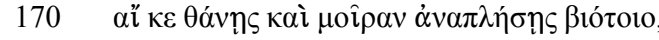
Il. IV 155-170 West.

Zeus Crónida no había querido dar cumplimiento a los juramentos entre

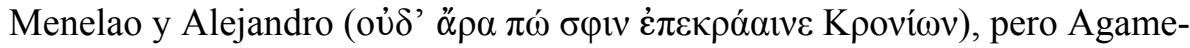
nón no duda de que, si el Olímpico no lo hace al momento ( $\alpha$ ủí́ '... oủк

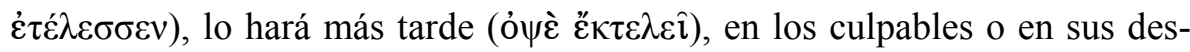

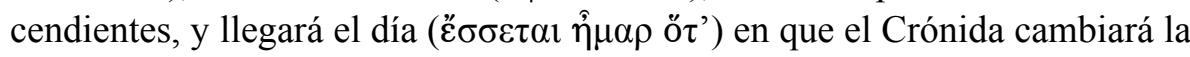
aflicción de Agamenón por la satisfacción de la venganza, aunque sea tras haberle causado sufrimiento ( $\alpha$ ivòv $\ddot{\alpha} \chi 0 \varsigma)$ por la muerte de su hermano ( $\mu$ ồ-

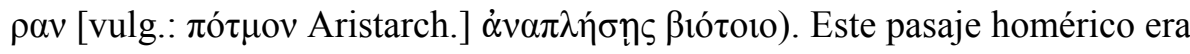
bien conocido para cualquier griego y debía constituir un ejemplo notable y estremecedor de los valores aristocráticos ${ }^{51}$. Casi todos los elementos del

51 «This is the first general statement in Greek literature of the powerful dogma that Zeus always exacts vengeance in the end, and that it may spread into the transgressor's family», Kirk ad 160-162. Cf. el mismo lugar sobre el tono gnómico de estos versos. 
final de la Pítica 12 aparecen en él, a veces con el mismo o muy parecido vocabulario, y con un tono gnómico semejante pero las diferencias de contenido son no menos interesantes, de tal modo que parece como si Píndaro hubiera modelado estas sentencias teniendo presente el espíritu del pasaje homérico, y a la vez en oposición ideológica con él.

La discrepancia más llamativa entre el pasaje de la Ilíada y nuestro texto

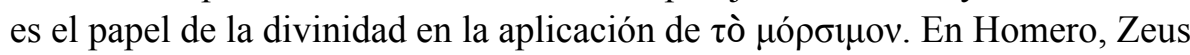
Olímpico puede no atender a los juramentos y dejar morir al inocente, pero el Crónida ejecutará el destino inexorablemente, bien en la persona del transgresor, o en las de sus descendientes. En Píndaro en cambio aparece un reparto de funciones entre el $\delta \alpha i ́ \mu \omega v$, que actúa inmediatamente y el tiempo, que lo hace más tarde.

Es muy importante llamar la atención sobre el orden de palabras del pasaje

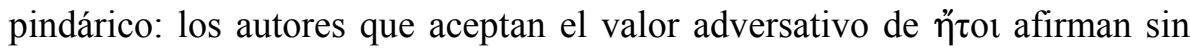
excepción que el término elidido es simplemente una expresión temporal (vg. $\alpha$ üpıov, Gentili p. XXXIX), pero debe notarse que tanto el sujeto ( $\delta \alpha i ́ \mu \omega v)$ como el término temporal ( $\sigma \alpha ́ \mu \eta \rho o v)$ han sido puestos detrás de la adversativa. Ello no puede ser casual, y opino que a ambos alcanza la elisión, como indican los versos 30 fin-32, y por esto debemos concluir que el elemento elidido por Píndaro es doble, y el sentido del mensaje inacabado es "lo predestinado lo cumplirá Zeus inmediatamente, o Cronos, más adelante". El porqué de la omisión lo veremos a continuación.

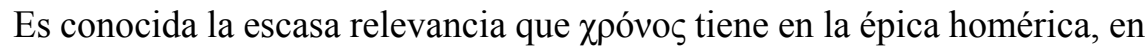
contraste con el importante papel que le reservan desde el siglo VI la filosofía y los poetas, en particular Píndaro. Komornika (p. 7 ss.) cita varios ejemplos donde $\chi \rho o ́ v o \varsigma$ en Píndaro aparece personificado y más cautelosamente Gerber afirma "'Time' in its various aspects is virtually personified in Pindar» (p.

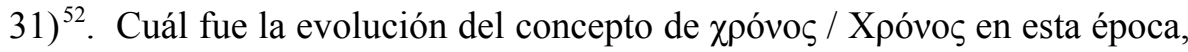
y su relación con Kóvos ha sido un tema sumamente debatido desde hace

52 Gerber continúa con esta llamativa observación: «The question however, of when words like chronos should be personified and therefore capitalized is difficult to determine. Obviously chronos is not personified to the degree that the Olympian gods are personified ... I

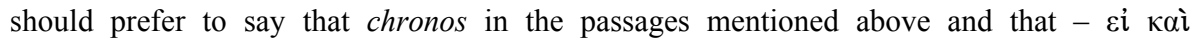
$\gamma \varepsilon \lambda$ oı́ $\tau \varepsilon \rho \circ$ vi $\varepsilon \varepsilon \hat{\imath} v$ - should be written with a mark halfway between a small and a capital letter», n. 6. Ni Komornika ni Gerber citan en sus respectivos estudios el presente texto. 
varias décadas ${ }^{53}$. Según las fuentes, quien primero colocó a Xpóvo

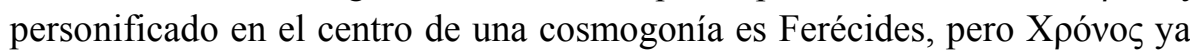
había sido identificado con Kóvos por los órficos ${ }^{54}$. Por diversos caminos el concepto adquirió un papel cada vez más importante en la visión filosófica del mundo de los griegos y a mediados del s. V el cómico Hermippo se permitía parodiar las especulaciones filosóficas sobre tiempo comunes en su época ${ }^{55}$. La concepción del tiempo de Píndaro está más cerca de los órficos que del "fundamento cosmogónico" de Ferécides, aunque en aquél no vemos la identificación Kpóvos / Xpóvos característica del orfismo: en O. 10.49 ss.,

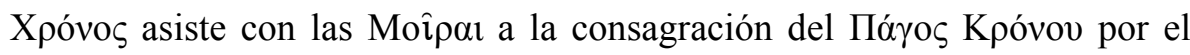
propio Zeus. Este texto muestra además la "solidaridad entre Moîpar y Xpóvos" característica de la época ${ }^{56}$ que es, a nuestro juicio, fundamental para entender nuestro pasaje.

Cómo llegó a adquirir Xpóvos (y no otro término) el papel que tiene en la filosofía de los ss. VI / V sigue siendo un problema. Si los antiguos vieron, como creemos, un paralelismo entre $I l$. IV 155-170 y el tipo de pasajes que hemos citado en los que el tiempo se encarga de dar cumplimiento a los designios divinos que Zeus no ejecuta inmediatamente, la oposición Zev̀s

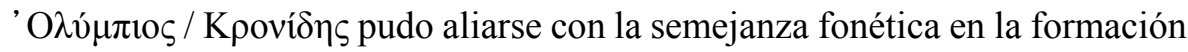
de este notable sincretismo.

Décadas más tarde, y quizá haciéndose eco del pasaje pindárico que estudiamos, Diágoras de Melos elaboraba una idea semejante en el encomio a Nicodoro de Mantinea, del que solamente nos han llegado dos versos: $\kappa \alpha \tau \grave{\alpha}$

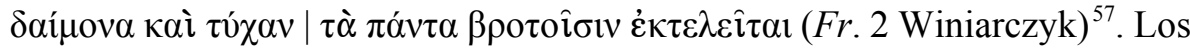
autores que nos han transmitido el fragmento de Diágoras "el ateo" (Phld., De pietate coll. 18-19, p. 85 Gömperz, S.E., Adv.Math. 9.53, etc.) lo dan como

\footnotetext{
53 Véase la bibiografía fundamental para esta cuestión en Komornicka, pp. 5 ss. y Martínez Nieto pp. 94-5.

${ }^{54}$ Y cf. Sol. 24.3 Adrados (= 36.3 West, quien considera a Xpóvo

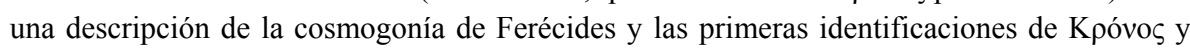
X९óvos, cf. Martínez Nieto, pp. 92 ss.

55 Fr. 73 Kassel-Austin, (= 4 Kock), cit. por Komornicka, p. 7 n. 7. El término usado es

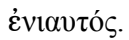

56 Cf. Degani, p. 121, y Komornicka, pp. 7 ss.

57 Véase una reconstrucción del contenido del poema, poco verosímil en mi opinión, (pero que acepta Winiarczyk) en Jacoby p. 14. Cf. Burkert p. 316 y n. 35 sobre el carácter del ateísmo de Diágoras.
} 
testimonio de la piedad del autor en los primeros tiempos de su producción poética. La tradición ha conservado el relato de que una desilusión de Diágoras respecto a la justicia de los hombres por un pleito particular le hizo cambiar radicalmente hasta convertirse en el ateo $\kappa \alpha \tau$ ' $\dot{\varepsilon} \xi o \chi \eta^{\prime} v$ de la antigüedad. La vida y obra de Diágoras está sumida en la casi total obscuridad, pero cabe preguntarse si la mencionada anécdota (que difícilmente puede explicar un cambio espiritual tan radical como el que pretendidamente se operó en Diágoras) no nació de las interpretaciones del texto al que pertenece el fragmento. Y de nuevo encontramos la misma idea de nuestros versos, con un vocabulario semejante, pero una formulación más

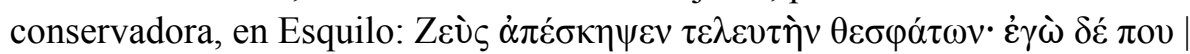
$\delta i \grave{\alpha} \mu \alpha \kappa \rho o \hat{~ \chi \rho o ́ v o v ~ \tau \alpha ́ \delta ' ~ \eta u ̛ \chi o v v ~ \varepsilon ̇ \kappa \tau \varepsilon \lambda \varepsilon v \tau \eta ́ ं \sigma \varepsilon เ v ~} \theta \varepsilon \circ u ́ \varsigma$, A., Pers. 740.

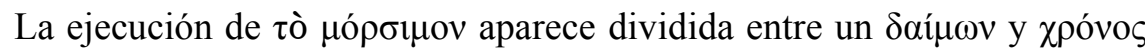

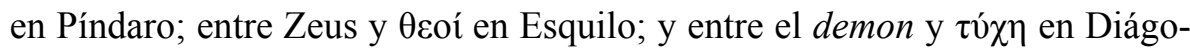
ras, en una dicotomía cara al pensamiento griego del s. V. Cualquier elaboración de las dos ideas fundamentales que subyacen a la cuestión (por qué la divinidad no actúa inmediatamente para restaurar los desequilibrios, y cómo se relaciona el demon con el fatum) debe moverse necesariamente en un terreno delicado para quien no pretenda ofender la creencia popular o la fe más ingenua, y Píndaro probablemente no quería ir tan lejos a la hora de atribuir un

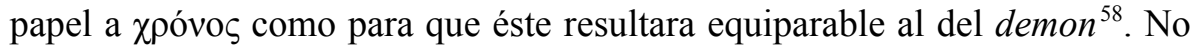

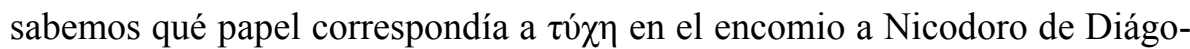
ras, quien con toda probabilidad trató con más extensión (¿quizás con imprudencia?) el papel de la divinidad y la fatalidad en el destino humano.

Podemos intentar ahora determinar cuál es el referente de viv. La co-

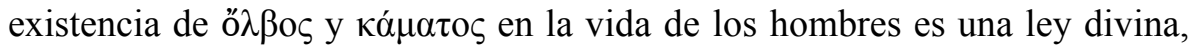
pero la ejecución de esta ley no es algo puramente mecánico, dejado en manos de unas fuerzas cósmicas. Se trata más bien del cumplimiento individual de cada uno de los designios de la divinidad por actos singulares de su voluntad. Podemos decir que el demon ejerce continuamente esta ley sobre la vida de cada hombre, y esto mismo, la ejecución de esta ley enunciada en el v. 28, es a lo que se está refiriendo Píndaro al afirmar $\dot{\varepsilon} \kappa \delta \grave{\varepsilon} \tau \varepsilon \lambda \varepsilon v \tau \alpha ́ \sigma \varepsilon \imath$ viv

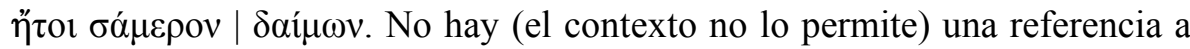
Midas, ni da buen sentido que tomemos singularmente ő $\lambda \beta 0 \varsigma$ o кó $\mu \alpha \tau \sigma \varsigma$

58 Cf. Bowra 1964, p. 87 ss., donde se discute Pae. 6.92-98 (=Fr. 52f) e I. 8.34-48. 
como el objeto del verbo. Para aceptar esta interpretación no es obstáculo el pronombre $v i v$, que puede referirse a una oración entera, como vemos en varios lugares de Píndaro ${ }^{59}$, ni el tipo de complemento de $\dot{\varepsilon} \kappa \tau \varepsilon \lambda \varepsilon v \tau \hat{\alpha} v$, que igualmente puede ser una oración ${ }^{60}$. Como ya se ha visto, el complemento de este verbo es rara vez algo concreto; es cierto que no he encontrado otro caso de $\dot{\varepsilon} \kappa \tau \varepsilon \lambda \varepsilon v \tau \hat{\alpha} \nu$ en el que lo que se haga cumplir sea la propia $\theta \varepsilon ́ \mu ı \varsigma$ divina, en lugar de las manifestaciones individuales de la voluntad del dios, pero no me

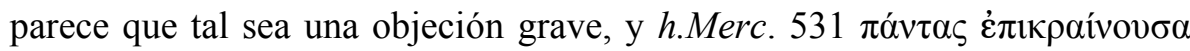

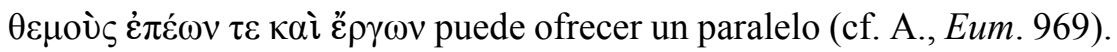

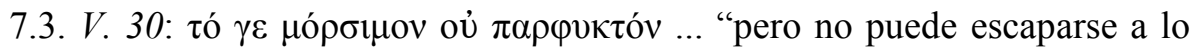
fijado por el destino".

Esta sentencia, que ocupa el lugar donde el público esperaría oír el

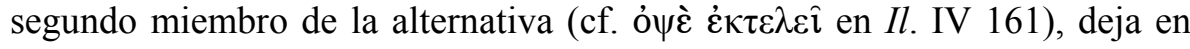
suspenso la formulación pindárica del problema de la distribución de funciones entre las potencias que ejecutan el designio divino, sólo para hacer una reafirmación previa de "piedad tradicional": todo designio divino que es $\mu$ ópøupov termina por llevarse a cabo. La vida nos traerá bienes y desgracias, y es inútil resistirse a ello, o esperar que la vida sólo depare felicidad y calma después del triunfo.

Aunque apenas relevante para el sentido, parece necesario, ponderando los argumentos paleográficos, leer aquí la partícula $\gamma \varepsilon$, que tendría el habitual valor de refuerzo. Un uso comparable (aunque no idéntico) lo encontramos en diálogos (especialmente en comedia y tragedia) donde el discurso interrumpido de un personaje es completado por la respuesta con $\gamma \varepsilon$ del

59 «Dans un certain nombre d'exemples, on est amené à trancher entre une anaphore de mot et une anaphore de proposition, la question revenant a choisir entre une anaphore segmentale et une anaphore résomptive» Hummel, p. 201. La autora cita dubitativamente (pp.

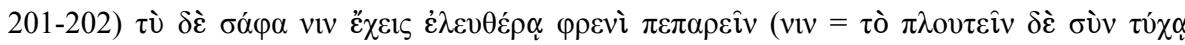

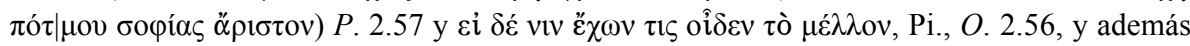
$O .7 .61, P .8 .16$ y $¡ 12.28-30$ !, aunque esto parece un error de interpretación, pues se presenta como la propuesta de Köhnken 1971, p. 148, quien en la traducción citada por Hummel y más claramente en la explicación de p. 149 declara: «viv sc. ő $\lambda \beta o v »$.

${ }^{60}$ En el otro ejemplo de $\dot{\varepsilon} \kappa \tau \varepsilon \lambda \varepsilon v \tau \alpha \dot{\omega} \omega$ en Píndaro, el complemento también es una

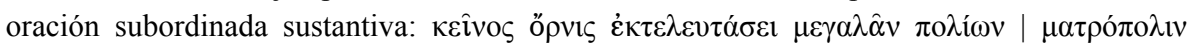

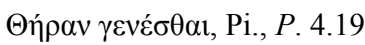




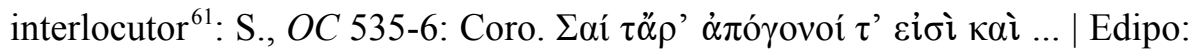

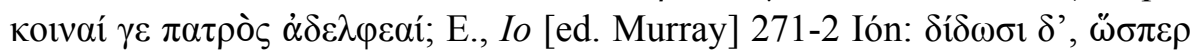

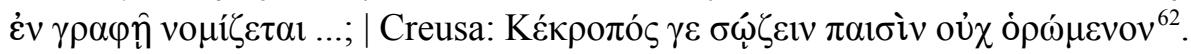

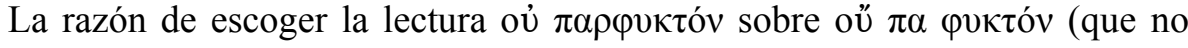
afecta al presente argumento) sigue siendo, fundamentalmente, dar preferencia a la lectio difficilior pues los criterios paleográficos a favor de la lectura alternativa no son decisivos en este caso.

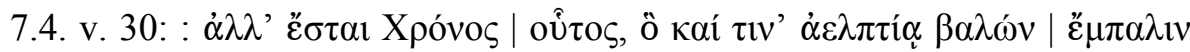

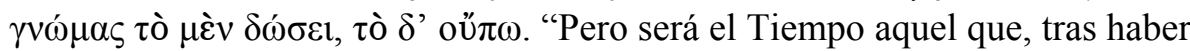
alcanzado a alguien con lo inesperado, en contra de sus previsiones, le dará esto, pero aquello otro aún no".

El autor sigue empleando en esta sentencia el futuro gnómico. Insistimos:

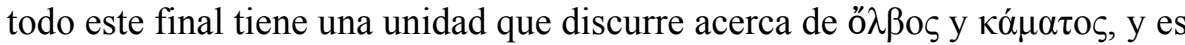

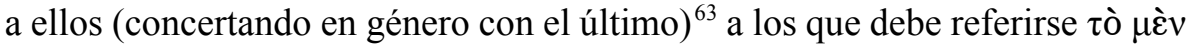
... $\tau$ ò $\delta \varepsilon ́$..., como indica el singular del pronombre y el juego de partículas. La

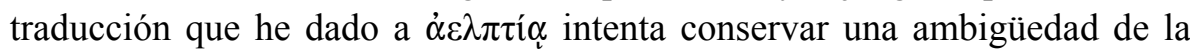
sentencia, pues es fundamental tener en cuenta que 'esto' 'lo otro' pueden referirse alternativamente a ő $\lambda \beta \varsigma_{\text {o }}$ o kó $\mu \alpha \tau o \varsigma$. Ambos están presentes entre los hombres necesariamente, y no se da el primero sin el segundo, por lo que se engaña quien disfruta la presente felicidad creyendo que ya nunca tendrá su parte de la otra mitad de su lote. Si uno se ha presentado ya, el otro lo hará más adelante.

Sin tener en cuenta la argumentación anterior, no es fácil resolver cómo hay que tomar $\chi \rho o ́ v o \varsigma$ ov̉ explicar el papel del sujeto agente de la oración, y el tiempo futuro de la oración invitan a ver Xpóvoৎ personificado, como sujeto de la oración de la que oữos ő ... es el atributo. Xpóvos, el encargado vicariamente de realizar los designios de los dioses, es aquí en siguiente lugar el agente engañoso que

61 «In drama, the speech of one character is sometimes completed by a second, who either (a) interrupts, or (b) carries on a sentence which is already complete in itself», Denniston, p. 137.

62 Compárese este valor con el que ante una semejante interrupción del poeta tiene $\delta \varepsilon ́$ en la oración que retoma el curso de la oda en $O .2 .58$.

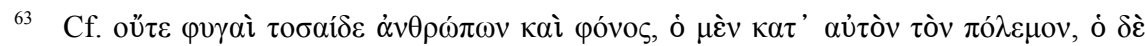

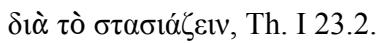


encontramos en Píndaro y Sófocles de manera eminente entre los poetas

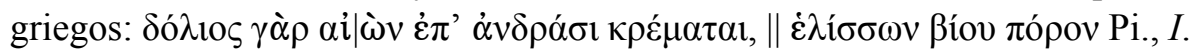
8.14 , cf. S., OC $607 \mathrm{ss.}^{64}$

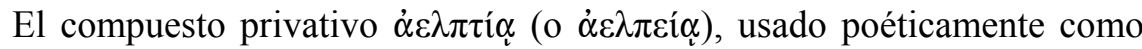
instrumental de $\beta \alpha ́ \lambda \lambda \omega$, presenta una doble interpretación que da mayor

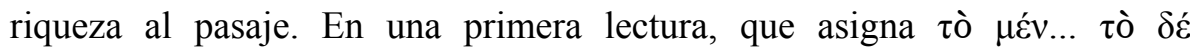

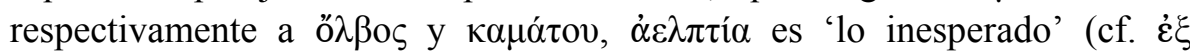
$\dot{\alpha} \varepsilon \lambda \pi \tau i n \varsigma$ Archil. 105.3 West [= 163.3 Adrados]), que sacude a quien ha recibido y disfruta de ő $\lambda \beta o \varsigma$, y confía en que nunca le llegará su otra parte del lote. Pero en la otra interpretación significa que el que sufre largamente

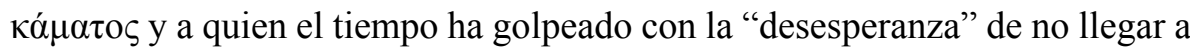
ver el fin de su dolor, debe esperar la llegada de la dicha ${ }^{65}$. En este tipo de sentencias Píndaro suele limitarse a indicar que hay ambas cosas en la vida, lo que en el contexto es una grave admonición que parece sugerir cierto pesimismo $^{66}$, pero una idea semejante sobre la alternancia de ő $\lambda \beta$ o $\varsigma$ y

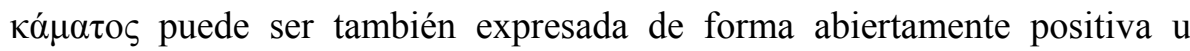

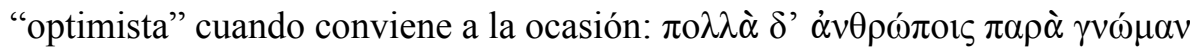

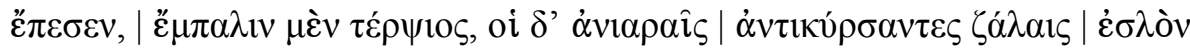

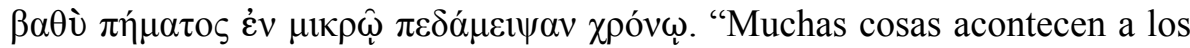
hombres en contra de sus deseos, en contra a veces de sus placeres, mientras otros, tras haberse encontrado con penosas tempestades, al poco tiempo cambia en gozo intenso su pesar". $O$. 12.10-12.

\section{Conclusión}

Píndaro desarrolla en este final gnómico lo que a la vista de los pasajes examinados podemos considerar un topos de la literatura griega: "lo que Zeus no hace cumplir inmediatamente, lo ejecutará el tiempo (u otra divinidad), si ese es el destino", pero debe hacerlo con la debida prudencia, pues el tema está en el centro de la controversia filosófico-religiosa de la época. El poeta expone esta nueva concepción de la providencia en unas máximas donde, excepcionalmente, no encontramos referencias al vencedor de la prueba

${ }^{64}$ Cf. Opstelten p. 173 y n.2, y Greene p. 142. La noción contraria en Pi., O. 10.55, cf E., Fr. 112.Nauck.

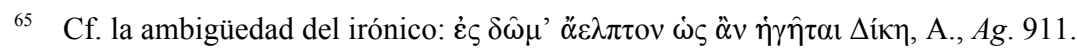

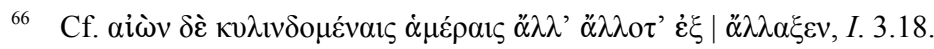


agonística. El pasaje discurre y tiene unidad como una reflexión sobre la necesaria alternancia de dicha y dolor en la vida de los hombres, entendida como una ley divina.

Llegamos aquí al final del desarrollo de esta concepción de la providencia divina en Píndaro, o mejor dicho, de todo cuanto Píndaro querría decir en una ocasión tan solemne acerca de este inquietante asunto. Probablemente Diágoras iba mucho más lejos en el desarrollo de su concepción del Fatum.

\section{REFERENCIAS}

Adrados, Francisco R. 1981: Líricos griegos. Yambógrafos y elegiacos. Vol. 1. 2 ed., Madrid, CSIC.

Alsina Clota, José 1988: Píndaro. Epinicios. Barcelona.

Bádenas, Pedro y Bernabé, Alberto 1984: Píndaro. Epinicios. Madrid.

Bischoff, Heinrich 1938: Gnomen Pindars. Würzburg.

Bowra, Cecil Maurice 1935: Pindari carmina cum fragmentis. Oxford.

- 1964: Pindar. Oxford.

Böckh, August 1811-1821: Pindari opera quae supersunt. Leipzig.

Bradford Welles, C. 1966: «Pindar's religion and the Twelfth Pythian Ode», YClS 19, pp. 79100.

Bremer, Dieter 1992: Pindar. Múnich.

Burkert, Walter 1985: Greek religion. [Trad. John Raffan]. Cambridge, Massachusets.

Burton, R.W.B. 1962: Pindar's Pythian Odes. Oxford.

Christ, Wilhelm von 1896: Pindari carmina prolegomenis et commentariis instructa. Leipzig.

Degani, Enzo 1960: AISN. Da Omero a Aristotele. Florencia.

Denniston, J.D. 1934: The Greek particles. Oxford.

Ellendt, Friedrich 1872: Lexicon Sophocleum. 2 ed. Berlin.

Farnell, Lewis Richard 1932: The works of Pindar. Londres.

Fennell, C.A.M. 1893: Olympian and Pythian Odes. Cambridge.

Fränkel, Hermann 1955 [1968 $]$ : Wege und Formen frühgriechischen Denkens. Múnich.

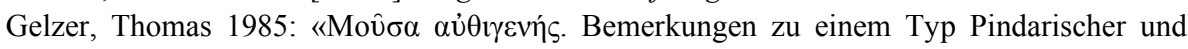
Bacchylideischer Epinikien». MH 42, pp. 95-120.

Gentili, Bruno 1995: Le Pitiche, (Intr. test. crit. e trad. di Gentili, Bruno; Commento a cura di Paola Angeli Bernardini, Ettore Cingano, Bruno Gentili e Pietro Giannini.) Milán. Citado como "Gentili".

- 1996: Poesía y público en la Grecia antigua. Barcelona.

Gentili, Bruno - Luisi, Francesco 1995: «La Pitica 12 di Pindaro e l'aulo di Mida». QUCC 49, pp. 7-31.

Gerber, Douglas E. 1999: Greek iambic Poetry. Cambridge

Gildersleeve, Basil L. 1885: The Olympian and Pythian Odes. Nueva York.

Greene, William Chase 1944 (1963): Moira. Fate, Good and Evil in Greek thought. Harvard. 
Herwerden, Henricus van 1827: «Pindarica». Mnemosyne 25 (n.s.), pp. 50-51

Hummel, Pascale 1993: La syntaxe de Pindare. Lovaina-París.

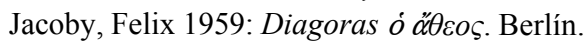

Kaibel, Georg 1884: «Sententiarum liber tertius». Hermes 19, pp. 246-263.

Kirk, G.S. 1985: The Iliad: A commentary. Vol. 1 books 1-4. Vol. 1. Cambridge.

Köhnken, Adolf 1971: Die Funktion des Mythos bei Pindar. Interpretationes zu sechs Pindargedichten. Berlín-Nueva York.

— 1976: «Perseus' Kampf und Athenes Erfindung (Bemerkungen zu Pindar, Pythien 12)». Hermes 104, pp. 257-265.

Komornicka, Anna M. 1976: «La notion du temps chez Pindare. Divers emplois et aspects du terme 'chronos'». Eos 44, pp. 5-15.

Krüger, Karl Wilhelm - Cooper, Guy L. 1998: Attic Greek prose Syntax. Michigan.

Lattimore, Richmond 1947: The Odes of Pindar. Chicago.

Lauts, U. H. 1797: Pindars Sentenzen. Leipzig.

Martínez Nieto, Roxana Beatriz 2000: La aurora del pensamiento griego. Madrid.

Méautis, George 1956: «Pindarica». RPh. 30, pp. 224-230.

Mezger, Friedrich 1880: Pindars Siegeslieder. Leipzig.

Norwod, Gilbert 1945: Pindar. Berkeley.

Opstelten, Johannes Cornelis 1952: Sophocles and Greek pessimism. Amsterdam.

Pardini, Alessandro 1997: «Pind. Pyth. 12,30: OY ПАІ ФYКТОN», RhM 140 (3-4), pp. $412-$ 413.

Pavese, Carlo Odo 1990: «Pindarica II». Eikasmos 1, pp. 37-82.

Pellizer, Aetius - Tedeschi, Ianuarius 1990: Semonides. Testimonia et fragmenta. Roma.

Pfeijffer, Ilia 1991: «Die Bedeutung von EKTEAEYTAN in Pi.P.12.29», Mnemosyne 44, pp. 410-412.

Puech, Aimé 1922: Pythiques, París.

Sandys, J.E. 1937: The odes of Pindar. Cambridge.

Schlesinger, Eilhard 1968: «Pindar, Pyth. 12», Hermes 96, pp. 275-285.

Schmidt, Leopold 1862: Pindars Leben und Dichtung. Bonn.

Schröder, O. 1922: Pindars Pythien. Leipzig.

Schwyzer, Eduard - Debrunner, Albert 1950: Griechische Grammatik. II: Syntax und syntaktische Stilistik. Múnich.

Snell, Bruno - Mähler, Herwig 1960: Pindari carmina cum fragmentis. Leipzig.

Strohm, Hans 1944: TYCHE. Stuttgart.

Suárez de la Torre, Emilio 1988: Píndaro. Madrid.

Thummer, E. 1968-9: Die Isthmischen Gedichte. Heidelberg.

Turyn, A. 1948: Pindari carmina cum fragmentis. Cracovia.

Vivante, Paolo 1972: «On time in Pindar». Arethusa 5, pp. 107-131.

Werner, Oskar 1967: Pindar. Múnich.

Wilamowitz-Moellendorf, Ulrich v. 1922: Pindaros. Berlín.

Winiarczyk, M. 1979: «Diagoras von Melos: Wahrheit und Legende. I». Eos 67, pp. 191-213.

- 1980. «Diagoras von Melos: Wahrheit und Legende. II». Eos 68, pp. 51-75.

- 1981. Diagorae Melii et Theodori Cyrenaei reliquiae. Leipzig. 